NASA/TM-1998-208836

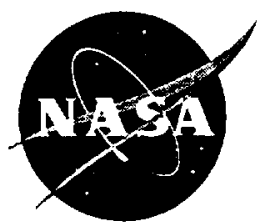

\title{
Tone Noise and Nearfield Pressure Produced by Jet-Cavity Interaction
}

Ganesh Raman

Dynacs Engineering Co., Inc. Brook Park, Ohio

Edmane Envia and Timothy J. Bencic

Lewis Research Center, Cleveland, Ohio

Prepared for the

37th Aerospace Sciences Meeting \& Exhibit

sponsored by the American Institute of Aeronautics and Astronautics

Reno, Nevada, January 11-14, 1999

National Aeronautics and

Space Administration

Lewis Research Center 


\section{Acknowledgments}

Insightful comments provided by Drs. A. Cain, S.H. Walker, M.J. Stanek, and L.L. Shaw are gratefully acknowledged. Dr. R.M. Nallasamy and Mr. John Wolter provided careful reviews and constructive comments. We thank Mr. W.O. Hughes and M.E. McNelis for bringing to our attention information pertaining to cavity resonance problems with the Titan commercial launch vehicle. The authors also thank Dr. J. Panda for providing a computer routine for the phaseaveraged measurements and Dr. Carolyn R. Mercer and Mr. Ken Weiland for the Schileren expertise. Engineering support in the areas of facility operations, fabrication/installation and electronics instrumentation provided by Ms. Gwynn Severt, Mr. James Nichols, and Mr. James Little is highly appreciated.

NASA Center for Aerospace Information 800 Elkridge Landing Road

Linthicum Heights, MD 21090-2934

Price Code: A03
National Technical Information Service 5287 Port Royal Road Springfield, VA 22100 Price Code: A03 


\title{
Tone Noise and Nearfield Pressure \\ Produced by Jet-Cavity Interaction
}

\author{
Ganesh Raman' \\ Dynacs Engineering Co., Inc. \\ Propulsion Analysis Section \\ NASA Lewis Research Center Group \\ Brook Park OH 44142 \\ Edmane Envia ${ }^{2}$ \\ Acoustics Branch \\ NASA Lewis Research Center \\ Cleveland, $\mathrm{OH} 44135$ \\ and \\ Timothy J. Bencic ${ }^{3}$ \\ Optical Instrumentation Technology Branch \\ NASA Lewis Research Center \\ Cleveland, $\mathrm{OH} 44135$
}

\begin{abstract}
Cavity flow resonance can cause numerous problems in aerospace applications. While our long-term goal is to understand cavity flows well enough to devise effective cavity resonance suppression techniques, this paper describes a fundamental study of resonant tones produced by jet-cavity interaction at subsonic and supersonic speeds. Our specific jet-cavity configuration can also be used as a test bed for evaluating active and passive flow resonance control concepts. Two significant findings emerge from this study.
\end{abstract}

1) Originally, we expected that tones produced by jet-cavity interaction would resemble cavity tones or jet tones or would involve some simple combinations of each. The experimental data do not support these expectations: instead, the jetcavity interaction produce a unique set of tones. We propose simple yet and physically insightful correlations for these tones. Although the pressure patterns on the cavity floor display very complex variations with the Mach number for a length/depth $=8$ cavity, the tones correspond to the acoustic modes of the cavity-independent of flow. For a length/depth $=3$ cavity, however, a surprise emerges: the pressure patterns on the cavity floor are not so complex but the tones depend significantly on the flow. Additionally, we examine the role of external feedback unique to jet-cavity interaction.

2) Previous research led us to expect that traditional classifications (open, transitional, or closed) for cavities in an infinite flight stream

${ }^{1}$ Senior Research Engineer, Associate Fellow, AIAA.

${ }^{2}$ Aerospace Engineer, Senior Member, AIAA.

${ }^{3}$ Electronics Engineer.

Copyright $\odot 1999$ by G. Raman. Published by the American Institute of Aeronautics and Astronautics, Inc. with permission. 
would be insensitive to small changes in Mach number and would depend primarily on cavity length/depth ratios. Use of the novel high resolution photoluminescent pressure sensitive paint shows that the classifications are actually quite sensitive to jet Mach number for a length/depth $=8$ cavity. However, these classifications provide no guidance whatsoever for tone amplitude or frequency.

Detailed experimental data and insights presented here will assist researchers who are performing numerical simulations of jet-cavity flows as a first step toward devising resonance suppression methods.

\section{Introduction}

\subsection{Motivation}

Flows over cavities occur in aircraft weapons bays, wheel wells, in-flight refueling ports, pressure vents in the space shuttle's cargo bay, and a host of other applications. Flows over cavities exhibit significant changes in the steady and unsteady nearfield pressure that are critical in both aeronautical and space applications (McNelis \& Hughes (1998), private communication). Air Force Research Labs (AFRL), Air Force Office of Scientific Research (AFOSR), National Aeronautics and Space Administration (NASA), Naval Air Weapons Center (NAWC), and Defense Evaluation and Research Agency (DERA, UK), have all initiated new coordinated weapons bay aeroacoustic control programs to enhance the ability to dispense weapons over a larger flight envelope without fatigue failure. A consortium entitled Active Robust ConTrol of Internal Cavities (ARCTIC) made up of the government agencies listed above, and including major airframe contractors, small companies, and universities, was formed to help focus efforts and enhance coordination. Although our work was done to support ARCTIC we focus on fundamental issues to better understand flows over cavities.

\subsection{Background}

Edge, cavity and screech tones are all ostensibly produced by very similar phenomena. These tones are generally attributed to embryonic disturbances in the shear layer that grow while convecting downstream and whose interaction with an edge, or shock-cell produces impulsive pressures that propagate upstream to close a resonant loop. Screech tones and jet-edge interactions have been studied by Powell $(1953,1961)$, Howe $(1981,1997)$, and Crighton (1992), among others. A review of advances in understanding screech was provided by Raman (1998). Despite the global similarity between edge, cavity and screech tones, there are intricate differences that make a universal frequency or amplitude model elusive. The need to study such fine differences between sub-classes of flow tones also motivated this work. Our focus is on the interaction of subsonic and supersonic shockcontaining jets with a cavity where both screech and cavity tones are theoretically permissible. However, it is important for us to present our results in the context of existing cavity resonance models especially because we wish to contribute to the design of cavity resonance suppression techniques. A brief review of the pertinent literature is given below.

The importance of the cavity problem to the aerospace sciences is evident from the vast number of papers written on this subject starting with the original work of Helmholtz in 1868 (Helmholtz (1954), Dover reprint). Models for resonant frequencies produced by flows over cavities were proposed by Rossiter (1962, 1966), East (1966), Bilanin \& Covert (1973), Block (1976), Tam (1976), and Tam \& Block (1978). Heller et al. (1971, 1973) and Heller \& Bliss (1975) made very significant contributions to our understanding of cavity resonance (and methods for its suppression) by providing a vivid description of physical mechanisms occurring during flow-cavity interaction. Heller's physical insights have been validated by many researchers and have thus stood the test of time. For further details the interested reader is referred to review papers by Rockwell \& Naudascher (1978), Komerath et al. (1987), Chokani (1992), Shaw (1979), and a handbook by Lucas et al. (1997). In the interest of brevity the above research is not discussed in great detail. However, for our purposes it is important to recognize Rockwell \& Naudascher's (1978) classification of cavity oscillations into three types: fluid dynamic, fluidresonant, and fluid-elastic. In the first type the cavity oscillations are driven solely by the instability of the shear layer, whereas in the second type, cavity oscillations result from the coupling of the inherent 
instability of the shear layer with one or more of the cavity's resonant acoustic modes. The third type of oscillation occurs only when the cavity has compliant walls. Our flow situation is fluid-resonant where further sub-classifications exist. When flow over the cavity is supersonic, Stallings \& Wilcox (1987) and Plentovich et al. (1993) classified the cavity flows to be open, transitional, or closed. When the shear layer spans the cavity opening the cavity is considered open, and when the shear layer attaches to the cavity floor the cavity is considered closed. Intermediate stages are considered transitional.

More recently the focus has shifted to active control of flows over cavities (Cattafesta et al. (1997), Shaw \& McGrath (1996)) because of the potential for these techniques to suppress resonance over a range of operating conditions for various cavity geometries. However, there is very limited information on the details of subsonic and supersonic shock-containing flows over cavities and pressure distributions in the nearfield. This current work studies in detail the nearfield pressures (both steady and unsteady) during jet-cavity interaction resonance. This paper presents experimental results aimed at understanding physical mechanisms responsible for large pressure amplitudes produced by flow-induced resonance in cavities.

\subsection{Objectives}

Tones produced by jet-cavity interaction are in some cases quite different from those produced either by shock-containing jets or by cavities in flight. Many details of the jet-cavity interaction problem remain to be understood. The first objective of this study, therefore, is to go beyond familiar polemics and raise fundamental questions about such complex resonant flows. The second objective arises from a more practical motivation: we intend to eventually use the jet-cavity configuration as a test bed for evaluating active and passive flow resonance control concepts. It is thus essential to understand practical differences (as well as similarities) between a cavity in an infinite flight stream and jet-cavity interaction. Included in the second objective is the unclear role of external feedback and the complex pressure distribution on the cavity floor. Our third and final objective is to provide both unsteady and steady benchmark data for those attempting to simulate complex cavity flows (e.g., the Cavity Acoustics
Modeling Software (CAMS) program at Boeing).

\subsection{Organization of paper}

In Section 2, we describe the jet-cavity arrangement and other experimental apparatus. Section 3.1 discusses (1) results from spark-schlieren flow visualization (2) correlations between microphones placed internal and external to the cavity, and (3) the role of external feedback. Section 3.2 covers tones produced by jet-cavity interaction and provides a basis to reconcile the frequencies of these tones. Section 3.3 documents in detail the phase-averaged acoustic nearfield of cavities and compares cavity data to that of jet screech. Finally, section 3.4 discusses the three types of supersonic cavity flows and documents photoluminescent pressure sensitive paint (PSP) results over a range of Mach numbers.

\section{Experimental details}

\subsection{Supersonic flow facility}

Experiments were conducted in a supersonic jet facility at the NASA Lewis Research Center. An existing jet nozzle was modified by adding an adaptor to which we could attach rectangular cavities of various dimensions. The jet flow thus formed the flight stream over the cavity. The cavity dimensions were $D$ (depth) $=1.27 \mathrm{~cm}, W$ (width) $=$ $4.445 \mathrm{~cm}$, and L (length) varied from $3.81 \mathrm{~cm}$ to $10.16 \mathrm{~cm}$ to yield $\mathrm{L} / \mathrm{D}$ ratios between 3 and 8 . For a more detailed study we chose two cavities having $L / D=3$ and 8 . Figure 1 shows a sketch of the nozzle-cavity arrangement. Also shown in Fig. 1 are the location of the internal (cavity) and external microphones and the $x y$ and $x z$ measurement planes in the acoustic nearfield.

\subsection{Measurement techniques}

A spark schlieren system was used for flow visualization. The system included a Palflash light source, a microscope objective, two spherical mirrors (15.24cm dia., $91.44 \mathrm{~cm}$ focal length), and a vertical knife-edge. The light source consisted of an electric arc in an inert atmosphere of argon gas, that could produce a 1 microsecond pulse of high intensity light ( 4 Joules). Photographs were taken by allowing light from the knife-edge to fall directly on Polaroid film. 
The acoustic measurements were made using 0.635 cm (1/4 inch) dia. B \& $\mathrm{K}$ microphones. The microphone locations and measurement planes in the nearfield are shown in Fig. 1. The microphones were calibrated using a B \& $\mathrm{K}$ pistonphone calibrator, with corrections for day-to-day changes in atmospheric pressure. The sound pressure levels reported in this paper are in $\mathrm{dB}$ (relative to $20 \mu \mathrm{P}$ ). Phase-averaged measurements (see Panda (1996)) of the nearfield pressures were made using a reference microphone located at the nozzle exit and a measurement microphone that traversed the entire nearfield. The signal from the reference microphone was band-pass filtered about the screech frequency to eliminate phase jitter. Data were ensembleaveraged over 100 oscillation cycles. The data acquisition rate $(200 \mathrm{KHz})$ was chosen such that we could compute the phase-averaged distributions for about 30 (typical) time steps per cycle.

\subsection{Photoluminescent pressure sensitive paint}

Pressure sensitive paint (PSP) was used to map the steady pressures within the cavity for various operating conditions. The principle of operation for these paints is well documented in the literature (Kavandi et al. (1990), McLachlan et al. (1992), Morris \& Donovan (1994)) and will only be mentioned briefly here. Certain chemical compounds when illuminated by light in a certain band of wavelengths exhibit luminescence. The luminescent light intensity is inversely proportional to the partial pressure of oxygen. The PSP used in our research was obtained from McDonnell Douglas Aerospace/Boeing (MDA PF2B). We primed the cavity with a glossy white base coat (MDA WAL-2) before applying the PSP. The NASA Lewis PSP system was described by Bencic $(1995,1998)$ and will only be briefly discussed here. Figure 2 depicts the imaging setup used in the current set of experiments. Two filtered, 75-Watt tungsten halogen lamps with integral reflectors placed in an air-cooled housing were used to excite the paint molecules. The light wavelength required for excitation ( 430 to $470 \mathrm{~nm}$ bandwidths) was obtained by selective band-pass filtering of the illumination lamps. Interference filters were used to pass light in the excitation band and reflecting unwanted light outside this band. The low-power light sources rendered the photolytic decomposition of PSP insignificant. The camera used in these experiments was a cooled scientific grade imager capable of 14bit resolution or approximately 16,000 intensity graduations. It had a spatial resolution of $512 \times 512$ pixels. The camera was optically filtered to allow only the luminesced light to be incident on the imager (detection band pass was from 530 to $650 \mathrm{~nm}$ ). The acquired images were processed using an intensity-based data reduction technique. This technique requires the two images, a "wind off" (Iref) reference image, and a "wind on" (Idata) data image to determine the magnitude of the pressure measurements. By taking the ratio of Iref and Idata, we corrected nonuniformities in paint application and lighting. An "a priori" or batch PSP calibration that depended on the composition of the paint was applied to the ratio image, and an "in-situ" calibration using data from static pressure taps on the cavity floor corrected the initial calibration.

\subsection{Temperature correction to minimize PSP errors}

When documenting pressure patterns on the cavity floor using PSP, one has to consider temperature variations caused by the jet flow on the cavity floor. Oglesby et al. (1996) have emphasized the importance of correcting PSP for temperature sensitivity, which is caused by at least three factors: (a) the luminescence process; (b) the solubility of oxygen in the paint matrix (especially when the luminophore is dissolved in a silicone polymer matrix); (c) the quenching reaction.

The correction was accomplished by first applying Temperature Sensitive Paint (TSP) to map the temperature on the cavity floor. The calibration for TSP included both "apriori" and "insitu" (using thermocouples on the cavity floor) methods. A temperature correction image was then generated using the expression $T_{\text {cor }}=1-\alpha \Delta \mathrm{T}$, where $\alpha=0.0047$ and $\Delta T$ is the change in temperature from the wind off images. Note that the constant $\alpha$ was determined by the paint manufacturer (McDonnell Douglas Aerospace/Boeing) for the paint used in this work. The PSP measurements were then corrected pointby-point by multiplying the PSP ratio intensity (Iref/Idata by $T_{\text {corr }}$. 


\section{Discussion of results}

\subsection{General aspects of jet-cavity interaction}

Fig. 3 shows spark schlieren photographs for the jet without the cavity and for cavities with $L / D=3,6$ and 8 at a fully expanded jet Mach number, $M_{j}=1.1$. At this Mach number the jet without a cavity (Fig. 3(a)) exhibits a weak antisymmetric oscillation downstream but no screech tones. However, strong tones were measured for all the cavity cases. Note that our cavity configuration is quite different from a cavity in an infinite flight because a shockcontaining jet forms the flight stream in our experiments. However, the simplicity of this set-up makes it a feasible test bed for evaluating cavity resonance suppression techniques. In addition the outer shear layer lets us visualize vortical events (shear layer instabilities) when the jet is excited by the jet-cavity interaction tone. Events occurring in the upper shear layer of the jet qualitatively correspond to those in the lower (albeit constrained) shear layer. For example in Fig. 3(b) highly energetic vortices are seen in the upper shear layer near the downstream end of the cavity and a later case displays the emission of a feedback shock (Fig. 3(d)). A higher Mach number case $\left(M_{j}=1.23\right)$ is shown in Fig. 4 (a-d). In this case the jet without a cavity produced an intense screech tone ( $f=2784$, $124 \mathrm{~dB})$. Complex shock structures are observed in all cavity cases. Again large-scale structures are visible in the upper shear layer of the jet, and feedback shock emission is seen in Figs. 4(b,c). So far our discussion has been concerned with cavities of $L / D=3,6$ and 8 . The rest of this paper will focus on the $\mathrm{L} / \mathrm{D}=3$ and 8 cases.

Figure 5(a) and 6(a) show spectra measured internal and external to the cavity. A microphone flush mounted on the cavity floor $(x / D=0.7, y / D=0)$ documented unsteady pressure levels occurring during cavity resonance. A second microphone outside the flow simultaneously recorded external signals in the near acoustic field (see Fig. 1 for microphone locations). From the internal and external microphone measurements, two observations can be made. First, the frequencies measured internal and external to the cavity are the same. Second, the amplitudes are about $30 \mathrm{~dB}$ higher inside the cavity. However, the relative dominance of the tones depends on the location of measurement.
The following notation is necessary to introduce the cross-spectrum and coherence functions. For two time-dependent signals, $A(t)$ and $B(t)$, autospectra $G_{A A}$ and $G_{B B}$, can be represented respectively as $\overline{\hat{A}(f) \bullet \hat{A} *(f)}$ and $\overline{\hat{B}(f) \bullet \hat{B} *(f)}$, where $\hat{A}(f)$ and $\hat{B}(f)$ are the Fourier transforms of $A(t)$ and $B(t)$. Note that ' $f$ denotes the frequency domain, the overbar denotes an average value, and the asterisk the complex conjugate. The cross-spectrum $\mathrm{G}_{\mathrm{AB}}$ can be represented as $\overline{A^{*}(t) \bullet B(f)}$. The linear spectral coherence $\gamma^{2}(f)$, is defined to be $\left|G_{A B}\right|^{2} / G_{A A} \bullet G_{B B}$. Note that $0 \leq \gamma^{2}(f) \leq 1$. The utility of $\gamma^{2}(f)$ lies in the fact that it expresses the degree of linear correlation between $A(f)$ and $B(f)$.

Figures 5(b) and 6(b) provide sample crosscorrelations for the two cavities at two Mach numbers. The data in Fig. 5 are for the $L / D=3$ cavity at $M_{j}=1.19$. Note the presence of two-tones a high cross-spectrum magnitude and a sharply peaked coherence. In contrast, for the data of Fig. 6 for an $L / D=8$ cavity at $M_{j}=0.6$, the coherence is high not only at the tone frequency but over the entire range from 0 to $3 \mathrm{KHz}$. This indicates the presence of broadband components of cavity noise that are correlated to the radiated noise. The above results suggest that external feedback does influence the cavity tone. It is important to note that the external feedback mechanism does not exist when a cavity is exposed to a supersonic stream of infinite transverse extent. We explored the role of external feedback further by moving a reflector outside the nozzle exit to block external feedback. The reflector having dimensions of $28(\mathrm{y})$ by $22(\mathrm{z}) \mathrm{cm}$ was parallel to the plane from which the jet emerged and could be moved downstream by remote control. The results of this experiment are summarized in Table I. Note that although the blockage of external feedback can significantly alter the relative amplitudes of both tones, their frequencies are essentially unaltered.

In this connection it should also be noted that several researchers have shown (see review by Raman (1998)) that screech can be completely eliminated by an appropriately positioned external reflector since all feedback to the nozzle exit is blocked. By way of contrast the present experiment includes both internal (within the cavity) and external (outside the jet) feedback. Blocking only external feedback does not eliminate the tones but it does alter their 
amplitudes.

\subsection{Tones produced by jet-cavity interaction}

Figures 7 and 8 show the frequency and amplitude, respectively, of various tones that occur when jets interact with cavities having $L / D=3$ and 8 . Note the presence of discrete frequency modes or stages of resonance (labelled I-III). On careful examination of the data of Umeda \& Ishii (1998), it is apparent that the frequency variations that we obtained were present in their data too. However, they did not highlight this point. An encouraging fact is that the frequency jumps could be reproduced in two independent and vastly different experimental facilities. Thus, the possibility of the results being facility dependent is highly improbable. It should be noted that the staging behavior is similar to that observed in screeching circular jets. In the absence of the cavity, the jet produces a flow resonance only when there are shocks (i.e., in the underexpanded regime). The frequency of this flow resonance (screech) ranged from $7616 \mathrm{~Hz}$ at $\mathrm{M}_{\mathrm{j}}=1.1$ to 2400 $\mathrm{Hz}_{2}$ at $\mathrm{M}_{\mathrm{j}}=1.32$. A peak screech amplitude of 135 $\mathrm{dB}$ was recorded during the experiments. The frequency versus $M_{j}$ curve for jet screech shown in Fig. 7(a,b) can be easily predicted using relationships proposed by Powell (1953), and Tam (1988).

Although the screech modes appear to be independent of cavity tones, they may still influence mode IB for the L/D $=3$ cavity and modes IIIB and IIB for the L/D $=8$ cavity. For the most part the cavity tone frequencies appear to increase with $\mathbf{M}_{\text {j, }}$, whereas the screech tone frequency decreases with $\mathrm{M}_{\mathrm{j}}$. This may initially come as a surprise since the mechanisms for tone production are remarkably similar. However, one should recognize that in the screech problem the shock-cell length increases with $M_{j}$ and that its increase with $M_{j}$ is more than twice the increase in convective velocity, and thus the decrease in frequency with increase in $\mathrm{M}_{\mathrm{j}}$. In contrast, for jet-cavity interaction, the location of the downstream edge is fixed and the travel time for disturbances to reach the edge decreases with increasing $M_{j}$ leading to the increase in frequency with $\mathbf{M}_{\mathbf{j}}$.

The data of Fig. 8 show that the tone's amplitude is both mode- and Mach-number dependent. Tone amplitudes generally increase with $\mathbf{M}_{\mathbf{j}}$, and multiple modes are present at mode transitions. From Figures 7,8 it is also clear that multi-modes are present for both cavities and that the cavity tone amplitude increases with L/D.

Correlations for tones produced by both cavities are shown in Fig. 9. One unique feature of our jet-cavity configuration is that, theoretically, both screech and cavity tones are permissible. Which, if any, of these tones appear is a point of curiosity that is quite easily checked. If screech tones were present, then one would expect them to at least qualitatively be predicted by Powell's (1953) formula given by

$$
\mathbf{f}=\frac{\mathbf{U}_{\mathrm{c}}}{\mathbf{S}\left(1+\mathbf{M}_{\mathrm{c}}\right)}
$$

where $f$ is the screech frequency, $U_{c}$ is the convective speed of the hydrodynamic disturbance, $S$ is the shock spacing, $M_{c}$ is the convective Mach number ( $\left.U_{d} / a\right)$, and $a$ is the speed of sound in the ambient medium.

On the other hand, if classical cavity tones dominate the spectrum, then they would be predicted by the Rossiter equation, which can be represented as

$$
\frac{\mathrm{fl}}{\mathrm{U}_{\infty}}=\frac{\mathrm{m}-\xi}{\mathrm{M}+1 / \mathrm{k}_{\mathrm{v}}}
$$

where

$$
\begin{aligned}
& k_{v}=\mathrm{U}_{\alpha} \mathrm{U}_{\infty}=\begin{array}{l}
\text { Ratio of disturbance convection } \\
\text { velocity to free stream velocity } \\
\text { (value of } 0.57 \text { suggested by Rossiter) }
\end{array} \\
& \mathrm{m}=1,2,3=\begin{array}{l}
\text { (Integers representing mode } \\
\text { numbers) }
\end{array} \\
& \xi=0.25 \text { (Empirical constant) } \\
& \mathrm{L}=\text { Cavity length } \\
& \mathrm{M}=\text { Fret stream Mach number }
\end{aligned}
$$

Our results are predicted neither by Powell's equation nor by Rossiter's. However, our results do exhibit clear trends. The $\mathrm{L} / \mathrm{D}=3$ cavity frequencies are well correlated by

$$
\mathrm{fL} / \mathrm{U}_{\mathrm{j}}=0.3 \mathrm{nM}_{\mathrm{j}}^{-1 / 2}(\mathrm{n}=1,2,3)
$$


and the $L / D=8$ results correlate with

$$
\mathrm{fL} / \mathrm{U}_{\mathrm{j}}=\frac{(\mathrm{n}+1)}{4 \mathrm{M}_{\mathrm{j}}}(\mathrm{n}=1,2,3)
$$

In both Eqns. (3) and (4) $f$ represents the frequency of the tone, $L$ the cavity length, $U_{j}$ and $M_{j}$ the fully expanded jet velocity and Mach number, respectively, and $\mathbf{n}$ is the mode index.

The latter relationship for the $\mathrm{L} / \mathrm{D}=8$ cavity can easily be reconciled with Tam's (1976) calculated normal mode frequencies for rectangular cavities as follows. Tam \& Block (1978) calculated the acoustic modes of rectangular cavities with no flow and showed that considerable insight can be obtained by examining these solutions. If we consider Tam's (1976) calculated frequency (the real part of $\omega L / a$ where $\omega=2 \pi f$ and $a=$ speed of sound in the ambient medium.) plotted versus $D / L$ for the lowest normal mode (cavity mode 1,1 ), then the frequency corresponding to $L / D=8$ is $\omega L / a=3$. On rewriting this it becomes $\frac{\mathrm{fl}}{\mathrm{U}_{\mathrm{j}}}=\frac{0.48}{\mathrm{M}_{\mathrm{j}}}$ which corresponds to the lowest mode of our correlation. It is indeed surprising that despite the complexity of the source region and the flow within the cavity, the frequencies are predicted using the acoustic modes of the cavity (calculated without flow). Thus, for the $\mathrm{L} / \mathrm{D}=\mathbf{8}$ cavity the flow does not appear to influence the cavity's acoustic modes.

In contrast, for the $\mathrm{L} / \mathrm{D}=3$ cavity, the tones produced do not match the cavity's acoustic modes. Note that Eqns. (3) and (4) can be re-written as $f l / a_{0}=0.3 n$ $M_{j}^{1 / 2}$ and $f L / a_{0}=(n+1) / 4$, respectively, where $a_{0}=$ speed of sound in the ambient medium. Thus, the non-dimensional frequency $\left(f \mathrm{~L} / \mathrm{a}_{0}\right)$ depends on $\mathrm{M}_{\mathrm{j}}$ for the $\mathrm{L} / \mathrm{D}=3$ cavity but not for the $\mathrm{L} / \mathrm{D}=8$ cavity.

It appears that at least three factors influence frequency selection in fluid-resonant cavities: (i) amplification of instabilities by the shear layer; (ii) cavity's the presence of a feedback mechanism; (iii) the natural acoustic modes. The eigenvalues and eigenfunctions from the linearized stability equations for realistic mean velocity profiles provide an envelope of possible frequencies. Since the linear theory deals with small perturbations, it can only predict the initial growth (locally) of a small perturbation. However, some insight can be obtained by examining the amplification envelope $\left(\alpha_{i}\right.$ versus $\omega$ curves, where $\alpha_{i}$ is the amplification rate and $\omega$ a non-dimensional frequency). The amplification envelope for 2D jets (see Cain \& Bower (1996) and Raman (1997)) is generally so wide that it covers $\hat{\omega}=0.02$ to 0.5 when $\hat{\omega}$ is defined to be $\left(2 \pi f / U_{j}\right)\left(\delta_{\omega} / 2\right)$ and the vorticity thickness $\delta_{m} / 2=2\left(y_{0.5}-y_{0.12}\right)$ where $y$ is the transverse co-ordinate of the jet and the subscripts refer to fractions of jet centerline velocity. In the above example the amplification envelope encompassed all screech and cavity frequencies observed in our experiments. Thus the frequency selection occurs primarily through (ii) and (iii) with (i) providing the requisite mechanism.

Appropriate closure of the feedback loop to satisfy the phase criterion (the arrival of an acoustic wave from the downstream edge matching the creation of an embryonic instability at the upstream edge) is thus critical in determining the screech frequency. Further, a super-resonance can be produced if these frequencies also match the acoustic modes of the cavity. Such a super-resonance does indeed appear to be present for our $\mathrm{L} / \mathrm{D}=8$ cavity. Direct evidence is provided by the frequencies matching the acoustic modes of the cavity and the tone amplitudes being 5 to $10 \mathrm{~dB}$ higher for this cavity than the $\mathrm{LD}=3$ cavity (for which the frequencies do not agree with the cavity's acoustic modes).

\subsection{Unsteady pressures in the nearfield of the cavity}

Phase-averaged pressure distributions in the nearfield on the $x z$ and $x y$ planes are shown in Figures 10 and 11 (for a description of the planes see Figure 1). In Figure 10 the vertical lines at the bottom denote the axial extent of the cavity. The arrows at the bottom of each frame are used to tag a region of the feedback wave and follow its progress upstream. The solid and dashed lines represent regions of the wave that are $180^{\circ}$ apart in phase. Note that the emission of the feedback wave occurs slightly ahead of the downstream edge of the cavity.

In Figure 11 additional horizontal lines on the y-axis denote the spanwise extent of the cavity. The purpose of including Figure 11 is to emphasize the lack of spanwise variations. Table II further 
substantiates this assertion. The data in Table II were obtained by moving a microphone in the $y$ direction at the nozzle exit plane $(x=0, y=3$ inches) and recording the coherence and relative phase with respect to a microphone located at $x=0$, $y=0, z=3$ inches. The phase variations in the $y$ direction are insignificant indicating that the tones are spanwise uniform; and the coherence function indicates that all tones have a high degree of spanwise coherence.

Figure 12 compares the phase-averaged data (at one phase of the reference signal) in the acoustic nearfield for a shock-containing screeching jet to that of a cavity tone. The difference in the character of the nearfield is perhaps due to a difference in the character of the source. One can think of two differences between screech and a cavity tone. Screech tones are produced by the interaction of the shear layer with shocks, whereas the cavity tone is produced by the interaction of the shear layer with the downstream edge of the cavity. The screech tone is amplified by the constructive interference of multiple shock-cell sources, whereas in the cavity tone a single source located close to the downstream edge dominates. However, a striking similarity between these two distinctly different physical situations is the presence of a feedback loop and the amplification of the tone through feedback. In Fig. 12 the solid and dashed lines represent phases of the acoustic feedback wave that are $180^{\circ}$ apart. The source configuration does appear to be quite different for the two cases, but in both cases the waves propagate upstream to close the resonant loop.

\subsection{Pressure variations on the cavity floor}

In a recent paper Stallings \& Wilcox (1987) reviewed the various classifications of cavity flows. In addition to classifying cavities as being deep (small L/D) or shallow (large L/D), we can also classify cavity flows as being open, closed, or transitional. When the shear layer spans the cavity opening, the cavity is considered open, and when the shear layer attaches to the cavity floor, the cavity is considered closed. Intermediate stages are transitional. Figure 13 (reproduced from Stallings \& Wilcox (1987)) depicts the three types of cavity flows and the associated pressure distribution on the cavity floor. Though much is known about the types of cavity flows, researchers still cannot agree on exact definitions. For example, Rossiter (1966) defined deep cavities as having $L / D<4$ and shallow cavities having $\mathbf{L} \mathbf{D}>4$. In contrast, Heller et al. (1971) and Shaw \& McGrath (1996) defined L/D = 1 as the dividing line to define deep and shallow cavities. The same is true of open, transitional, and closed cavity flows. Stallings \& Wilcox (1987), Plentovich et al. (1993), and Shaw \& MoGrath (1996) use very wide and differing bands to define these cavity types. Such startling discrepancies provided us the impetus for conducting a detailed study of the pressure distribution on the floor of the cavity for cavities with $L / D=3$ and 8 over a range of Mach numbers. We chose the pressure sensitive paint (PSP) technique because of the high spatial resolution it provides (equivalent to about 250,000 pressure taps) and because of our extensive previous experience with this technique in studying ejector wall pressures (Taghavi et al. (1997)).

When comparing the pressure distributions used by Stallings \& Wilcox (1987) to define open, transitional, and closed cavity flows with results of the present work, we should note two points. First, Stallings \& Wilcox (1987) defined $C_{p}$ as $\left(p-p_{\infty}\right) / q_{\infty}$ where $p$ is the cavity floor pressure, $p_{\infty}$ is the free stream static pressure and $q_{\infty}$ the free stream dynamic pressure. Our definition differs because we use $C_{p}=\left(p-p_{a}\right) / p_{a}$, where $p$ is the cavity floor pressure and $p_{a}$ is the ambient pressure. Second, the Stallings \& Wilcox (1987) diagrams (Figure 13) are valid only for a supersonic flight stream. In comparison our flow is comprised of subsonic, sonic, and supersonic shock-containing jets interacting with a cavity. However, we can still make useful qualitative comparisons with the Stallings \& Wilcox (1987) classifications.

PSP results are presented for the $L / D=3$ cavity in Fig. 14, and the centerline pressures from the PSP results are plotted in Fig. 15. From the PSP results we can deduce that the $L / D=3$ cavity is open. In the flow direction the $C_{p}=\left(\left(p-p_{2}\right) / p_{2}\right)$ values first decrease and then increase towards the downstream end of the cavity. In addition, spanwise variations appear to he insignificant on the cavity floor.

Similar results for the L/D $=8$ cavity shown in Figs. 16 and 17 provide an interesting contrast. Since all three types (open, closed, transitional) of cavity flows were possible here. In addition we note a very intriguing trend as the Mach number increases. 
Careful scrutiny of the color pressure maps reveals that the presence of (1) a subatmospheric pressure region immediately after the upstream edge of the cavity and (2) a high-pressure region closer to the downstream edge of the cavity. Note the spanwise variation in the pressure near the downstream edge of the cavity. As the Mach number increases from 0.615 to 0.97 , the pressure values and axial extent of the low-pressure region decrease while the pressures and the extent of the downstream high-pressure region increase. However, at supersonic Mach numbers $\left(M_{j}=1.02\right.$ to 1.32$)$ the trend reverses itself. A point of great interest here is not only the reversal of trend but the fact that $M_{j}=1$ demarcates the reversal in trend. Judging from the $\mathbf{C}_{\mathrm{p}}$ profiles in Fig. 17, it appears that for $M_{j}=0.615$ to 0.865 the cavity is transitional. At $M_{j}=0.97$ and 1.02 it becomes closed and finally it becomes open at higher Mach numbers. Thus our results emphasize the point that the open/closed classification of cavities distinctly depends on the Mach number. Thus, a cavity that is transitional at $\mathrm{M}_{\mathrm{j}}=\mathbf{0 . 8 6 5}$ could become closed at $M_{j}=0.97$ and then suddenly become open at $\mathrm{M}_{\mathrm{j}}=1.13$ ! These scenarios suggest that the lack of clear definitions perhaps arise due to the sensitivity of the shear layer to initial conditions, Mach number, and the presence and location of shocks.

Based on the vivid display (Figure 16 and Figure 17) of several distinct flow regimes over a small $M_{j}$ range for the $L / D=8$ cavity, one would expect that it would be very difficult to predict the tones produced by this cavity. Contrary to our expectations a simple relationship from section 3.2 (Eqn. 4) that depends only on the cavity's acoustic modes (and not on flow within the cavity) successfully correlates all tones. In contrast, the $L / D=3$ cavity that displays a relatively uniform pressure distribution on the cavity floor (Figure 14 and Figure 15) is not correlated by the cavity's acoustic modes but by Eqn. (3) that includes the effect of flow Mach number. It follows from our discussion that the pressure distribution on the cavity floor provides very little insight about the resonant tones. However, the various flow regimes are important considerations because the resonance suppression technique (active or passive) chosen for practical applications should work for all possible flow regimes.

\section{Conclusions}

Our study of jet-cavity interaction was motivated by the need to understand cavity flows well enough to devise effective cavity resonance suppression techniques. A series of experiments were performed on subsonic, sonic and supersonic jets interacting with cavities having length/depth ratios of 3 and 8 . In addition to spark-schlieren flow visualization and documentation of the tone frequencies and amplitudes of jets interacting with cavities, we also provided detailed maps of nearfield unsteady pressures. Additionally, we explored the role of extemal feedback that is absent with cavities in a supersonic flight stream but is present in our case. Time-averaged pressures on the cavity floor were studied using the novel photoluminescent pressure sensitive paint technique that had high spatial resolution and revealed complex pressure distributions on the cavity floor.

The following important results emerged from this study. (1) Jet-cavity interaction produced tones that were different from either jet screech or cavity tones. We proposed simple yet physically insightful correlations for these tones. Although the pressure patterns on the cavity floor displayed very complex variations with the Mach number for a length/depth $=8$ cavity, the tones corresponded to the acoustic modes of the cavity-independent of flow. For a length/depth $=3$ cavity, however, a surprise emerged: the pressure patterns on the cavity floor were not so complex but the tones depended significantly on the flow. (2) We showed that the traditional classifications (open, transitional, or closed) for cavities in an infinite flight stream depended primarily not on length/depth ratios as previously believed but also on the Mach number. Use of pressure sensitive paint showed that the classifications were actually quite sensitive to jet Mach number for a length/depth $=8$ cavity. However, these classifications provide no guidance whatsoever for tone amplitude or frequency. It is hoped that the detailed experimental data and insights presented here will be useful to those devising cavity resonance suppression techniques for use in practical applications and to those performing numerical simulations of jet-cavity flows. 


\section{Acknowledgements}

Insightful comments provided by Drs. A. Cain, S.H. Walker, M.J. Stanek, and L.L. Shaw are gratefully acknowledged. Dr. R.M. Nallasamy and Mr. John Wolter provided careful reviews and constructive comments. We thank Mr. W.O. Hughes and M.E. McNelis for bringing to our attention information pertaining to cavity resonance problems with the Titan commercial launch vehicle. The authors also thank Dr. J. Panda for providing a computer routine for the phase-averaged measurements and Dr. Carolyn R. Mercer and Mr. Ken Weiland for the Schlieren expertise. Engineering support in the areas of facility operations, fabrication/installation and electronics instrumentation provided by Ms. Gwynn Severt, Mr. James Nichols, and Mr. James Little is highly appreciated.

\section{References}

Bencic, T.J. 1995 Experiences using pressure sensitive paint in NASA Lewis Research Center propulsion test facilities. AIAA Paper 95-2831.

Bencic, T.J. 1998 Rotating pressure and temperature measurement on scale model fans using luminescent paints. AIAA Paper 98-3452.

Bilanin, A.J. \& Covert, E.E. 1973 Estimation of possible excitation frequencies for shallow rectangular cavities. AIAA J. 11, 347-351.

Block, P.J.W. 1976 Noise response of cavities of varying dimensions at subsonic speeds. NASA TN D-8351.

Cain, A.B. \& Bower, W.W. 1996 Modeling supersonic jet screech: differential entrainment and amplitude effects. AIAA Paper 96-0916.

Cattafesta, L.N. III, Garg, S., Choudhari, M. \& Li, F. 1997 Active control of flow induced cavity resonance. AIAA Paper 97-1804.

Chokani, N. 1992 Flow induced oscillations in cavities: A critical survey. AIAA Paper 92-02-159.

Crighton, D.G. 1992 The jet edge-tone feedback cycle; linear theory for the operating stages. J. Fluid Mech. 234, 361-392.
East, L.F. 1966 Aerodynamically induced resonance in rectangular cavities. J. Sound Vib. 3, 277-287.

Heller, H.H., Holmes, D.G. \& Covert, E.E. 1971 Flow-induced pressure oscillations in shallow cavities. J. Sound Vib. 18, 545-553.

Heller, H., Widnall, S., Jones, J. \& Bliss, D. 1973 Water table visualization of flow induced pressure oscillations in shallow cavities for simulated supersonic flow conditions. Paper Z13, 86th meeting of the Acoustical Society of America.

Heller, H.H. \& Bliss, D.B. 1975 The physical mechanism of flow induced pressure fluctuations in cavities and concepts for their suppression. ALAA Paper 75-491.

Helmholtz, H.L.F. 1954 Sensations of tone. 2nd edition, Dover, New York.

Howe, M.S. 1981 The influence of mean shear on unsteady aperture flow, with applications to acoustical diffraction and self-sustained cavity oscillations. J. Fluid Mech. 109, 125-146.

Howe, M.S. 1997 Edge, cavity and aperture tones at very low Mach numbers. J. Fluid Mech. 330, 6184.

Kavandi, J., Callis, J., Gouterman, M., Khalil, G., Wright, D, Green, E., Burns, D. \& McLachlan, B. 1990 Lur unescent barometry in wind tunnels. Review of Scientific Instruments 6, 3340-3347.

Komerath, N.M., Ahuja, K.K. \& Chambers, F.W. 1987 Prediction and measurement of flows over cavities a survey. AIAA Paper 87-022.

Lucas, M.J., Noreen, R.A., Sutherland, L.C., Cole, J.E. III, \& Junger, M.C. 1997 Handbook of the acoustic claracteristics of turbomachinery cavities. ASME Press, New York.

McLachlan, B.G., Kavandi, J.B., Callis, J., Gouterman, M., Khalil, G. \& Burns, D. 1993 Surface pressure field mapping using luminescent coatings. Experiments in Fluids 14, 33-41. 
McNelis, M.E. \& Hughes, W.0. 1998 Vent tones produced by the commercial Titan launch vehicle (private communication).

Morris, M.J. \& Donovan, J.F. 1994 Application of pressure and temperature sensitive paint to high speed flows. AIAA Paper 94-2231.

Oglesby, D.M., Upchurch, B.T., Leighty, B.D., Simmons, K.A. \& Demandante, C.G. 1996 Pressure sensitive paint with internal temperature sensing luminophore. Proc. 42nd Int. Inst. Symp. of ISA, pp. 205-224, San Diego, May 5-9.

Powell, A. 1953 On the mechanism of choked jet noise. Proc. Phys. Soc. Lond. 66, 1039-1056.

Powell, A. 1961 On the edgetone. J. Acoust. Soc. Am. 33, 395-409.

Panda, J. 1996 An experimental investigation of screech noise generation. AIAA Paper 96-1718.

Plentovich, E.B., Stallings Jr., R.L. \& Tracy, M.B. 1993 Experimental cavity pressure measurements at subsonic and transonic speeds. NASA TP 3358.

Raman, G. 1997 Cessation of screech in underexpanded jets. J. Fluid Mech. 336, 69-90.

Raman, G. 1998 Advances in understanding supersonic jet screech: review and perspective. Prog. Aerospace Sci. 34, 45-106.

Rockwell, D. \& Naudascher, E. 1978 Review of self-sustaining oscillations of flow past cavities. J. Fluids Engr. 100, 152-165.

Rossiter, J.E. 1962 The effect of cavities on the buffeting of aircraft. Royal Aircraft Establishment Tech. Mem. 754.

Rossiter, J.E. 1966 Wind-tunnel experiments on the flow over rectangular cavities at subsonic and transonic speeds. Aeronautical Research Council Reports and Memo No. 3438.

Shaw, L.L. 1979 Suppression of aerodynamically induced cavity oscillations. AFFDL-TR-79-3119.
Shaw, L.L. \& McGrath, S. 1996 Weapons bay acoustics: Passive or active control. AIAA Paper 961617-CP.

Stallings, R.L., Jr. \& Wilcox, F.J., Jr. 1987 Experimental cavity pressure distributions at supersonic speeds. NASA TP-2683.

Taghavi, R, Raman, G. \& Bencic, T. 1997 Visualization of ejector wall pressure using pressure sensitive paint. ASME Paper FEDSM 97-3236.

Tam, C.K.W. (1976) The acoustic modes of a twodimensional rectangular cavity. J. Sound Vib. 49, 353-364.

Tam, C.K.W. \& Block, P.J.W. 1978 On the tones and pressure oscillations induced by flow over rectangular cavities. J. Fluid Mech. 89, 373-399.

Tam, C.K.W. 1988 The shock cell structures and screech tone frequencies of rectangular and nonaxisymmetric supersonic jets. J. Sound Vib. 121, 135-147.

Umeda, Y. \& Ishii, R. 1998 Reduction of noise radiated from supersonic jet by interaction between the screech and cavity tones. ASME FEDSM 985240 . 


\begin{tabular}{|c|c|c|c|c|}
\hline $\begin{array}{l}\text { Reflector } \\
\frac{\mathrm{x}}{\mathrm{D}}\end{array}$ & $\begin{array}{c}\text { Amplitude of } \\
f_{1}=1664 \mathrm{~Hz} \\
(\mathrm{SPL}, \mathrm{dB})\end{array}$ & $\begin{array}{c}\text { Amplitude of } \\
\mathrm{f}_{2}=3328 \mathrm{~Hz} \\
(\mathrm{SPL}, \mathrm{dB})\end{array}$ & $\begin{array}{c}\gamma^{2}\left(f_{1}\right) \\
\text { Coherence between } \\
\text { internal and external } \\
\text { microphones at } f_{l}\end{array}$ & $\begin{array}{c}\gamma^{2}\left(f_{2}\right) \\
\text { Coherence between } \\
\text { internal and external } \\
\text { microphones at } f_{2}\end{array}$ \\
\hline 0 & 167.3 & 151.0 & 0.983 & 0.888 \\
\hline 0.5 & 168.2 & 151.4 & 0.984 & 0.900 \\
\hline 1.0 & 168.8 & 151.3 & 0.989 & 0.892 \\
\hline 1.5 & 169.3 & 150.5 & 0.992 & 0.886 \\
\hline 2.0 & 169.1 & 149.8 & 0.986 & 0.894 \\
\hline 2.5 & 169.1 & 150.4 & 0.987 & 0.927 \\
\hline 3.0 & 168.7 & 152.0 & 0.987 & 0.929 \\
\hline 3.5 & 167.2 & 146.9 & 0.991 & 0.866 \\
\hline 4.0 & 167.6 & 146.3 & 0.989 & 0.854 \\
\hline 4.5 & 166.1 & 153.7 & 0.980 & 0.774 \\
\hline 5.0 & 162.0 & 159.9 & 0.938 & 0.979 \\
\hline 5.5 & 164.6 & 159.0 & 0.914 & 0.959 \\
\hline 6.0 & 164.3 & 161.4 & 0.625 & 0.989 \\
\hline 6.5 & 162.5 & 163.8 & 0.712 & 0.974 \\
\hline
\end{tabular}

Table I: Role of external feedback on jet-cavity resonance illustrated by the axial movement of a reflector outside the flow. 


\begin{tabular}{|c|c|c|c|c|}
\hline & \multicolumn{2}{|c|}{$\mathrm{M}_{\mathrm{j}}=1.06$} & \multicolumn{2}{c|}{$\mathrm{M}_{\mathrm{j}}=1.23$} \\
& \multicolumn{2}{|c|}{$\mathrm{F}=1632 \mathrm{~Hz}$} & \multicolumn{2}{c|}{$\mathrm{F}^{2400 \mathrm{~Hz}}$} \\
\hline $\mathrm{y}$ & $\begin{array}{c}\text { Relative Phase } \\
\mathrm{D}\end{array}$ & $\begin{array}{c}\text { Coherence } \\
\gamma^{2}(\mathrm{f})\end{array}$ & $\begin{array}{c}\text { Relative Phase } \\
\Delta \phi / 2 \pi\end{array}$ & $\begin{array}{c}\text { Coherence } \\
\gamma^{2}(\mathrm{f})\end{array}$ \\
\hline-2.0 & -0.00305 & 0.997 & 0.00833 & 0.992 \\
\hline-1.6 & -0.00167 & 0.997 & 0.01111 & 0.992 \\
\hline-1.2 & 0.00 & 0.996 & 0.0108 & 0.993 \\
\hline-0.8 & -0.00194 & 0.997 & 0.00278 & 0.993 \\
\hline-0.4 & -0.00056 & 0.996 & 0.00445 & 0.994 \\
\hline 0.0 & 0.00 & 0.996 & 0.00 & 0.993 \\
\hline 0.4 & 0.00167 & 0.997 & -0.00305 & 0.993 \\
\hline 0.8 & -0.00223 & 0.997 & -0.00556 & 0.995 \\
\hline 1.2 & -0.00500 & 0.996 & -0.00638 & 0.993 \\
\hline 1.6 & -0.00528 & 0.997 & -0.0100 & 0.994 \\
\hline 2.0 & -0.0119 & 0.996 & -0.0130 & 0.995 \\
\hline
\end{tabular}

Table II: Spanwise phase and coherence 


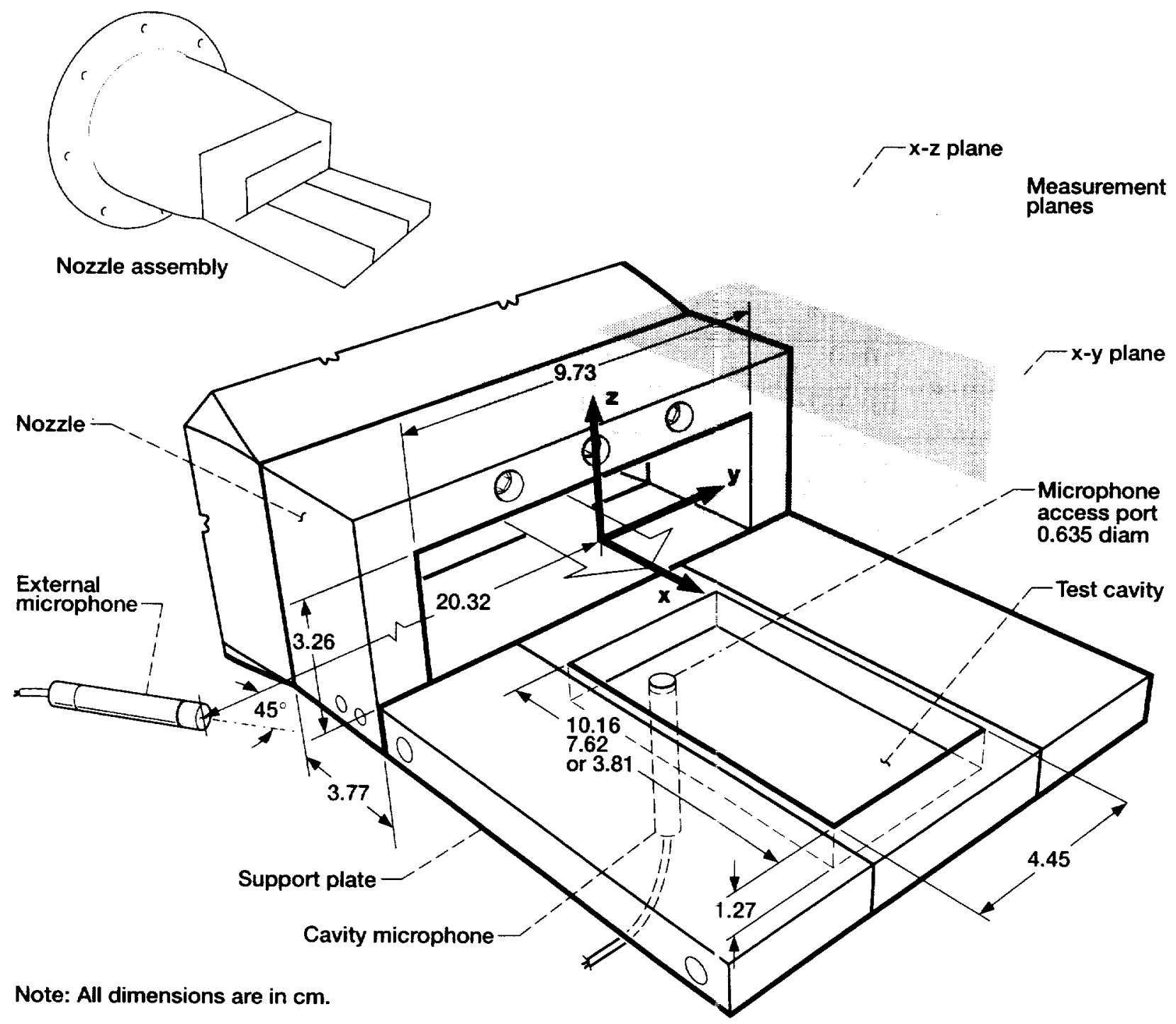

Figure 1.-Schematic showing jet-cavity configuration, micmphones and measurement planes. 


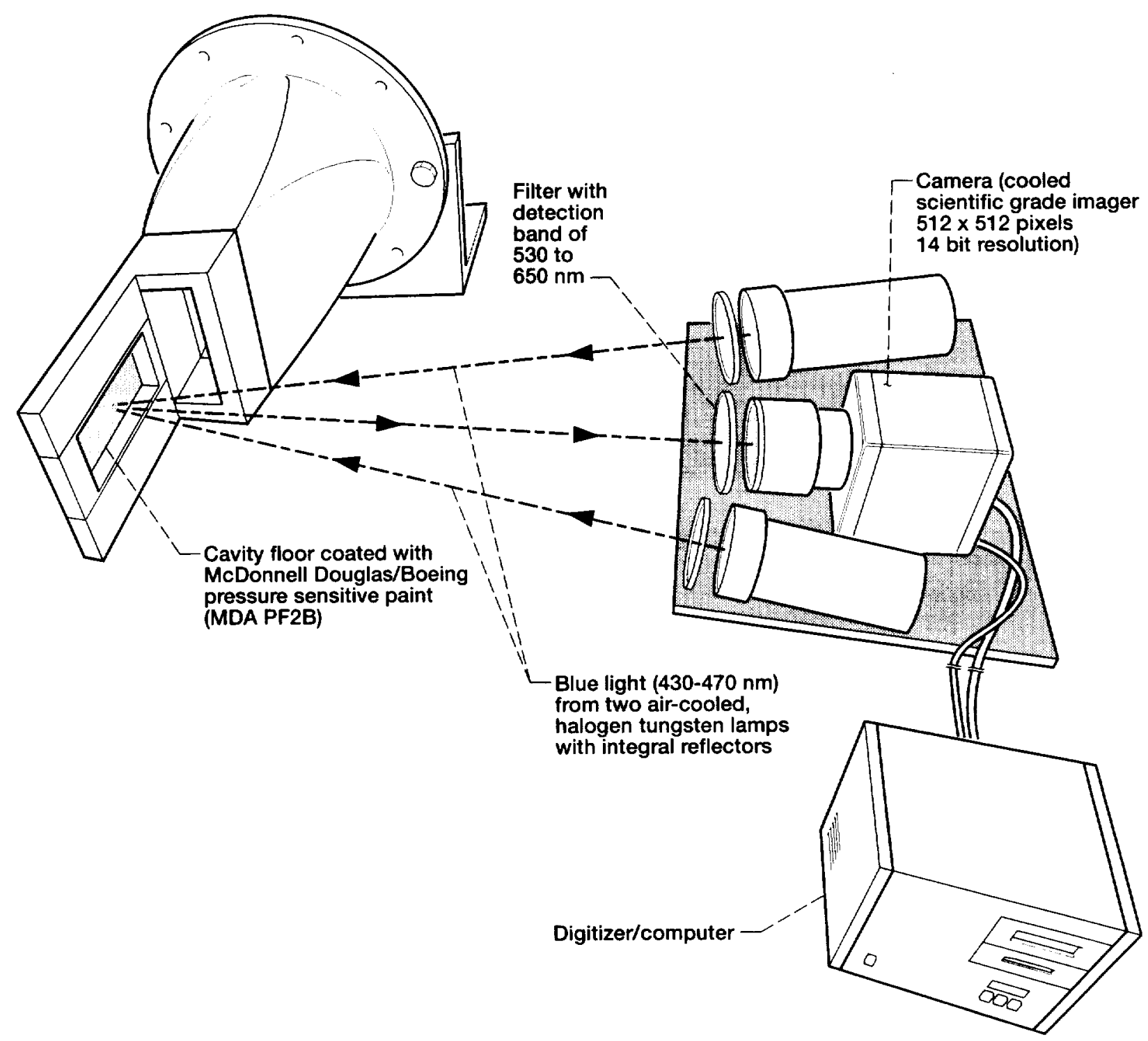

Figure 2.-Photoluminescent pressure sensitive paint apparatus. 

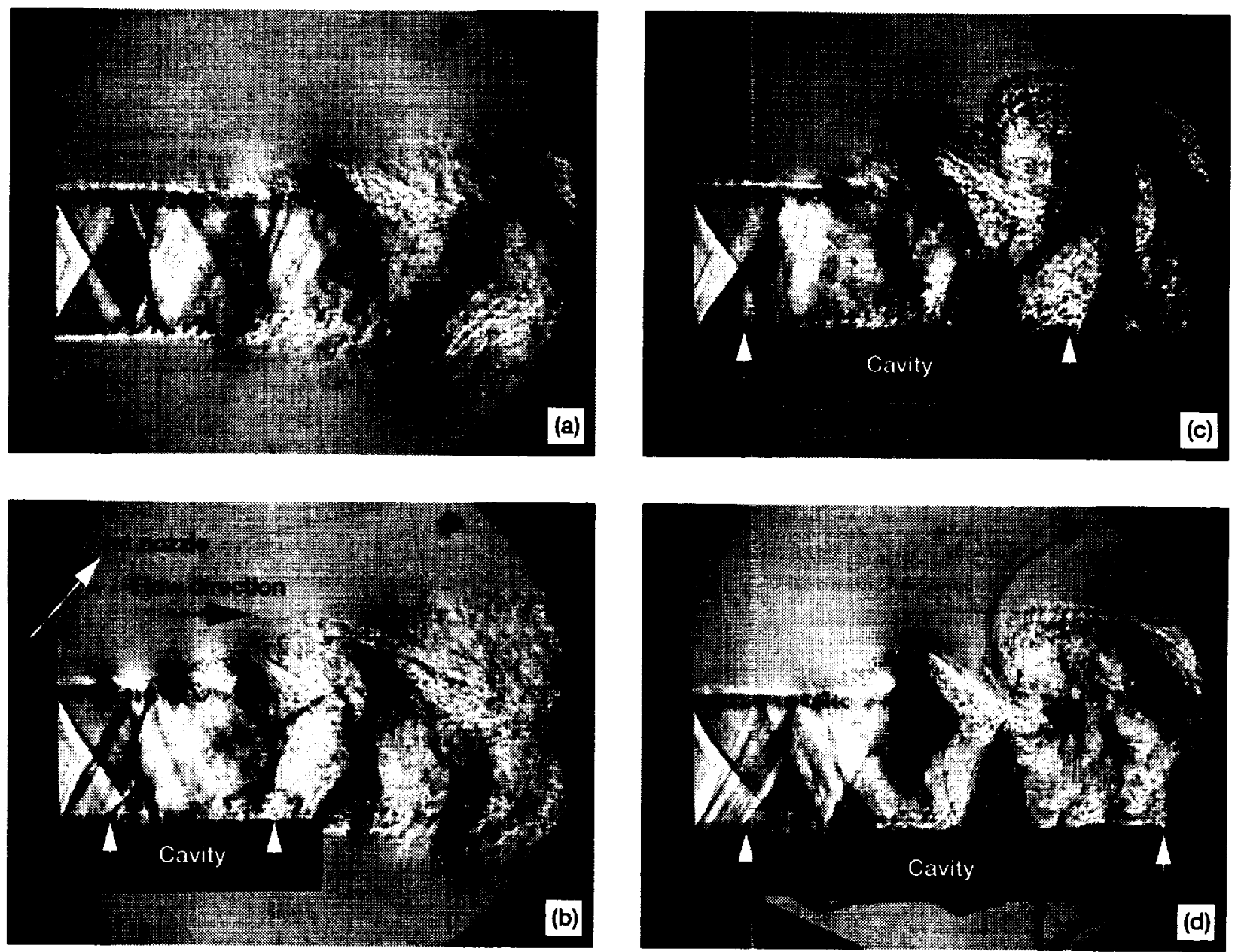

Figure 3.-Spark-schlieren photographs of jet-cavity interaction at $M_{j}=1.11$. View shows narrow dimension of jet. (a) Jet without cavity. (b-d) Jet with cavity. $L D$ (b) 3, (c) 6, (d) 8 . White arrows mark upstream and downstream edges of cavity. 

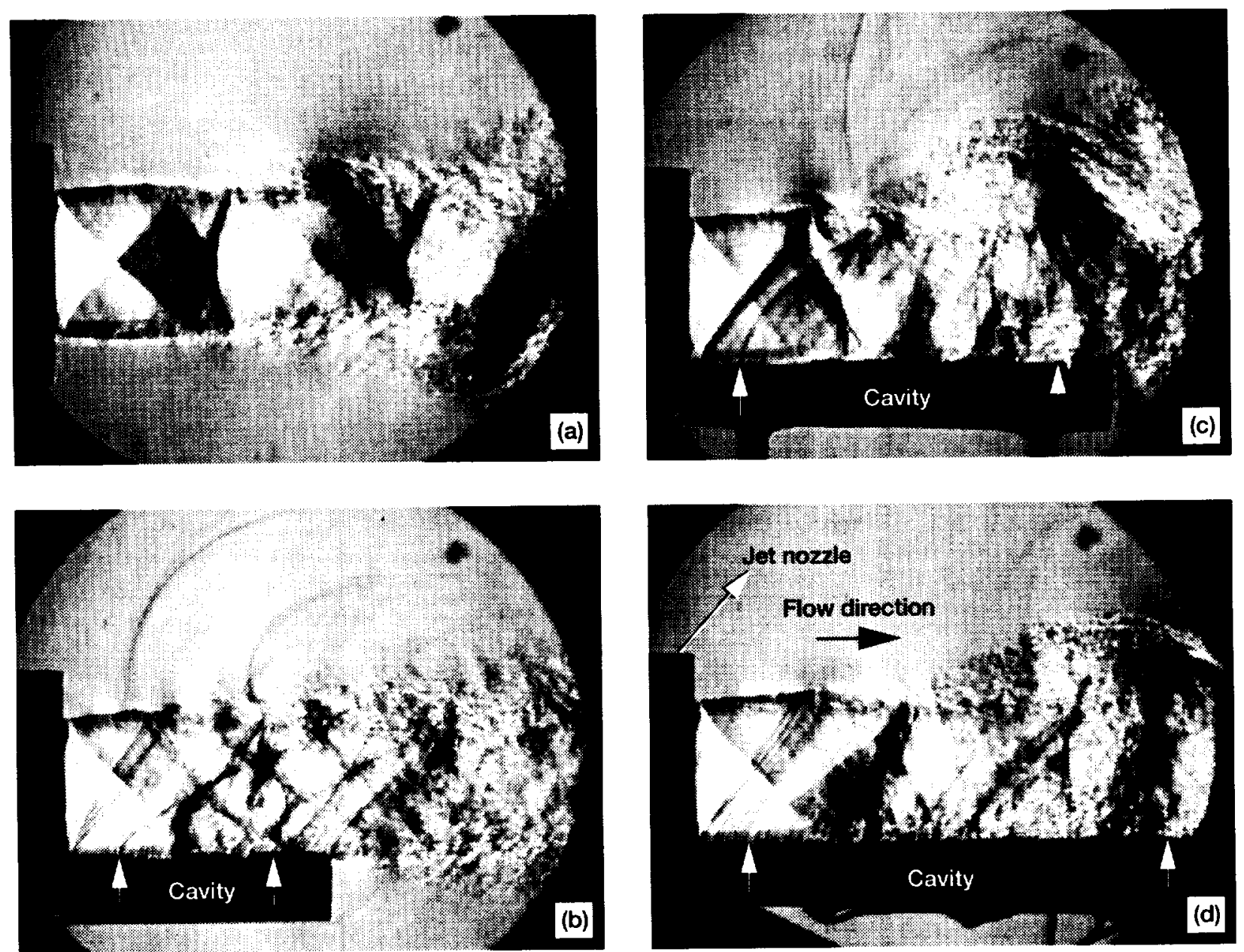

Figure 4.-Spark-schlieren photographs of jet-cavity interaction at $\mathrm{M}_{\mathrm{j}}=1.23$. View shows narrow dimension of jet. (a) Jet without cavity. (b-d) Jet with cavity. UD (b) 3, (c) 6, (d) 8. White arrows mark upstream and downstream edges of cavity. 

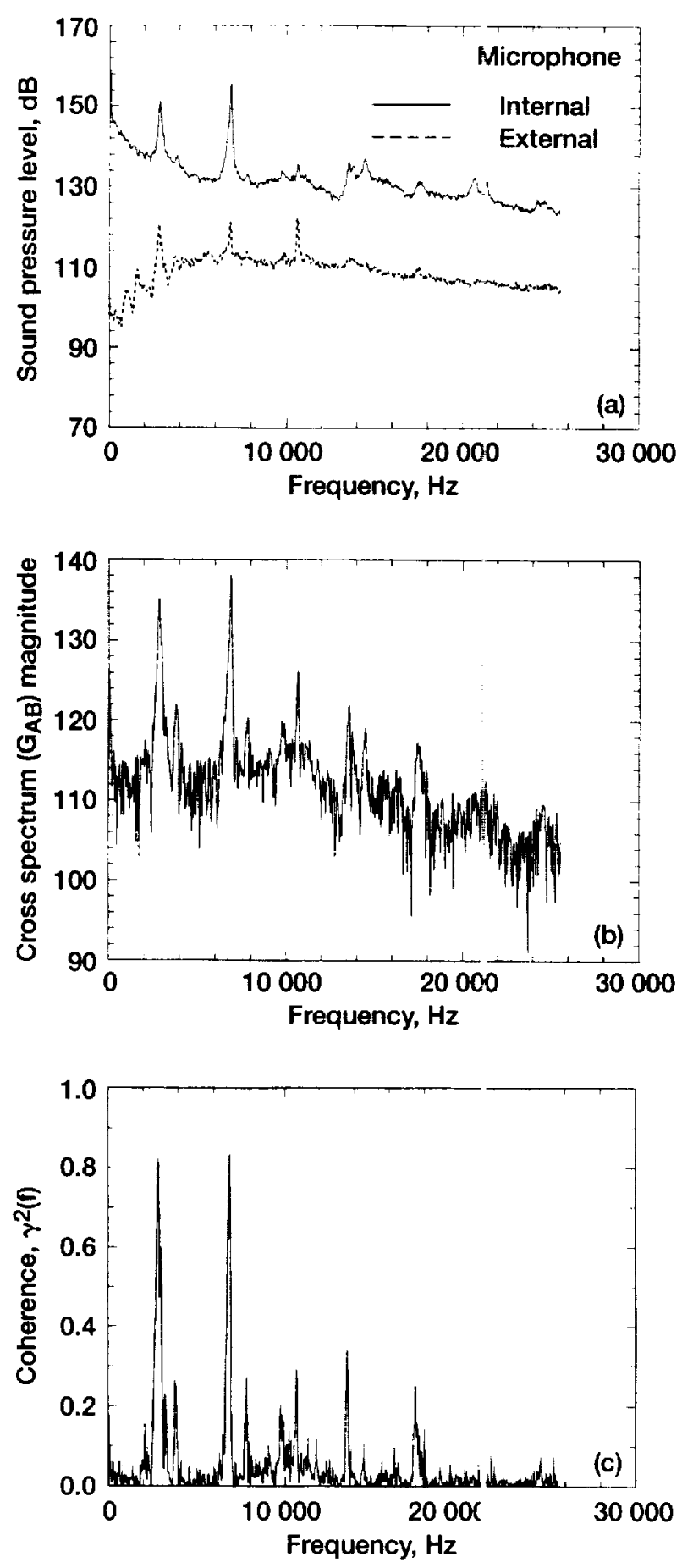

Figure 5.-Narrowband spectra from two-point microphone measurements. $M_{j}=1.19, L / D=3$ cavity. (a) Spectra from external and internal (cavity) microphones. (b) Cross-spectrum magnitude. (c) Linear spectral coherence. Internal microphone flush mounted on cavity floor at $x / D=0.7, y / D=0$. External microphone at $r / D=16$, oriented at $45^{\circ}$ on the xy plane (see Figure 1). 

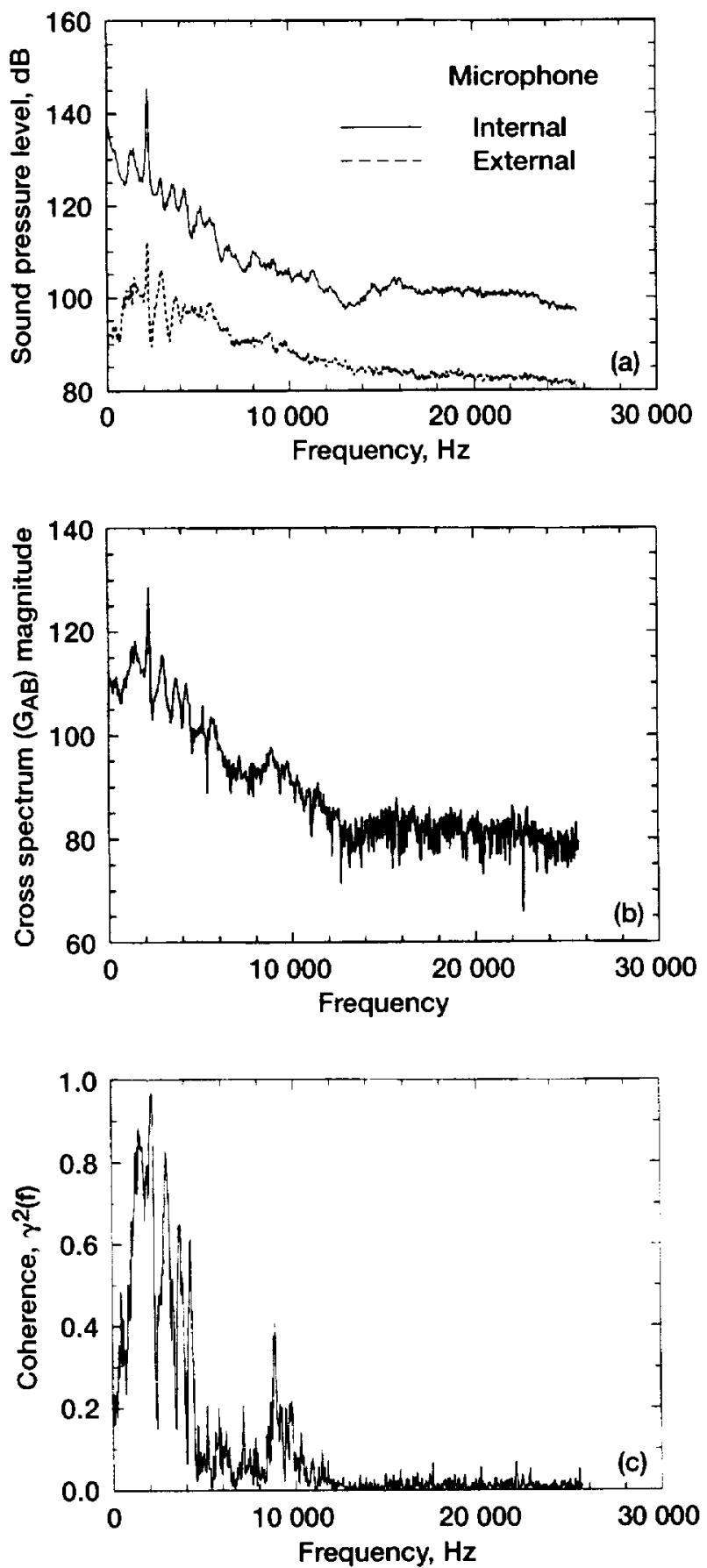

Figure 6.-Narrowband spectra from two-point microphone measurements. $M_{j}=0.60, L / D=8$ cavity.

(a) Spectra from external and internal (cavity) microphones. (b) Cross-spectrum magnitude. (c) Linear spectral coherence. Internal microphone flush mounted on cavity floor at $x / D=0.7, y / D=0$. External microphone at $r / D=16$, oriented at $45^{\circ}$ on the xy plane (see Figure 1). 

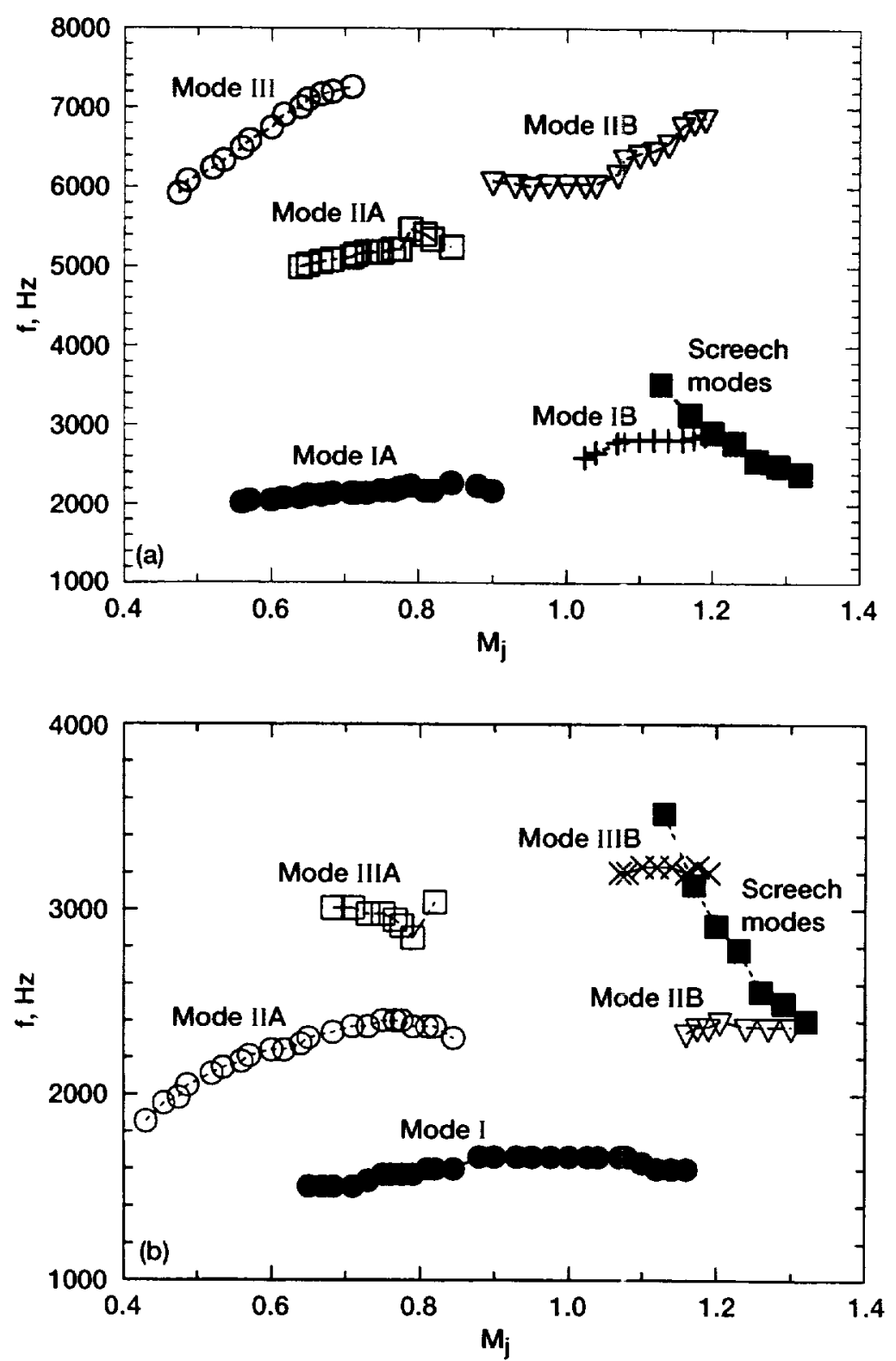

Figure 7.-Tone frequency produced by jet-cavity interaction versus fully expanded jet Mach number. (a) $L D=3$ cavity. (b) $L / D=8$ cavity. 

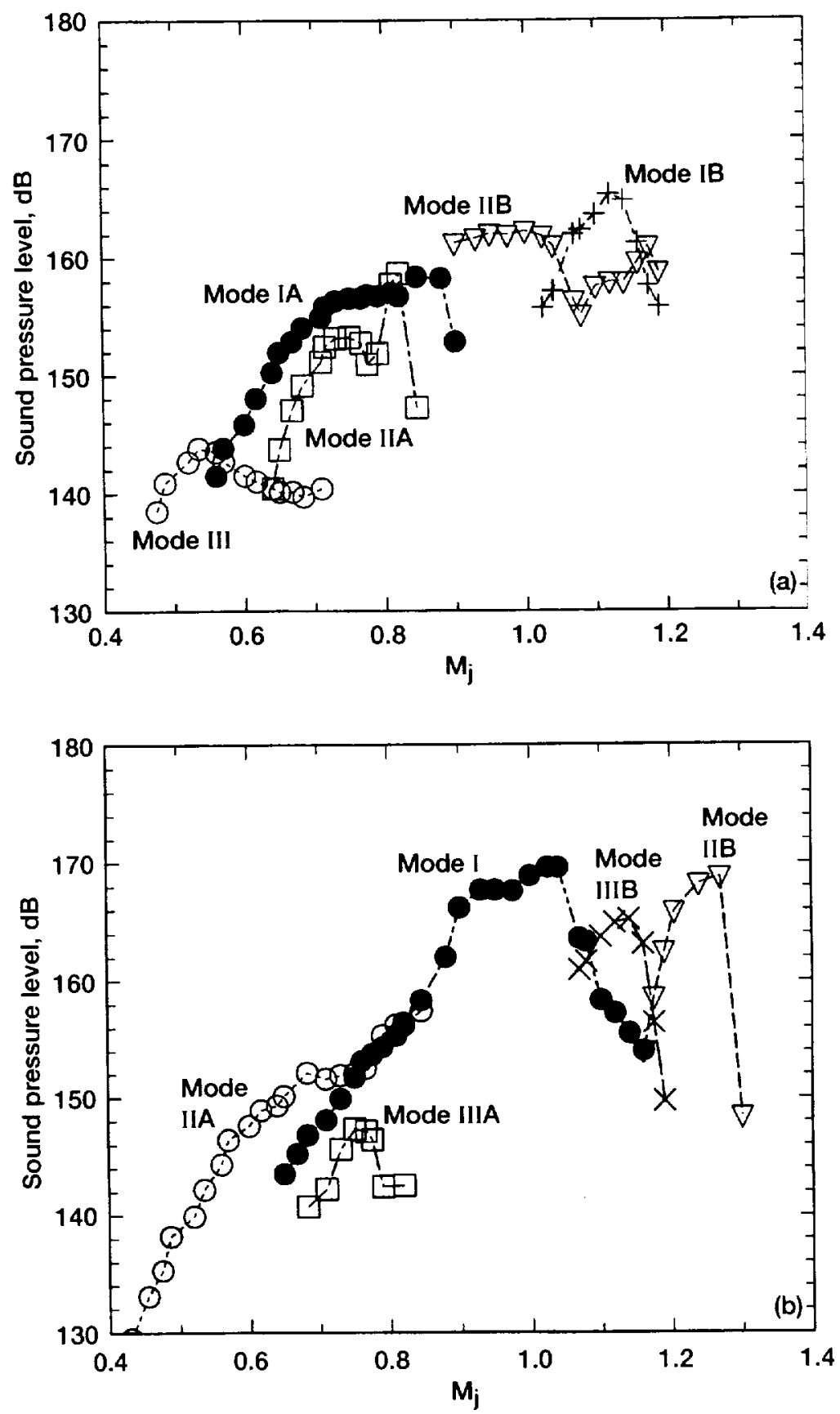

Figure 8.-Tone amplitude produced by jet-cavity interaction versus fully expanded jet Mach number. (a) $L D=3$ cavity. (b) $L / D=8$ cavity. 

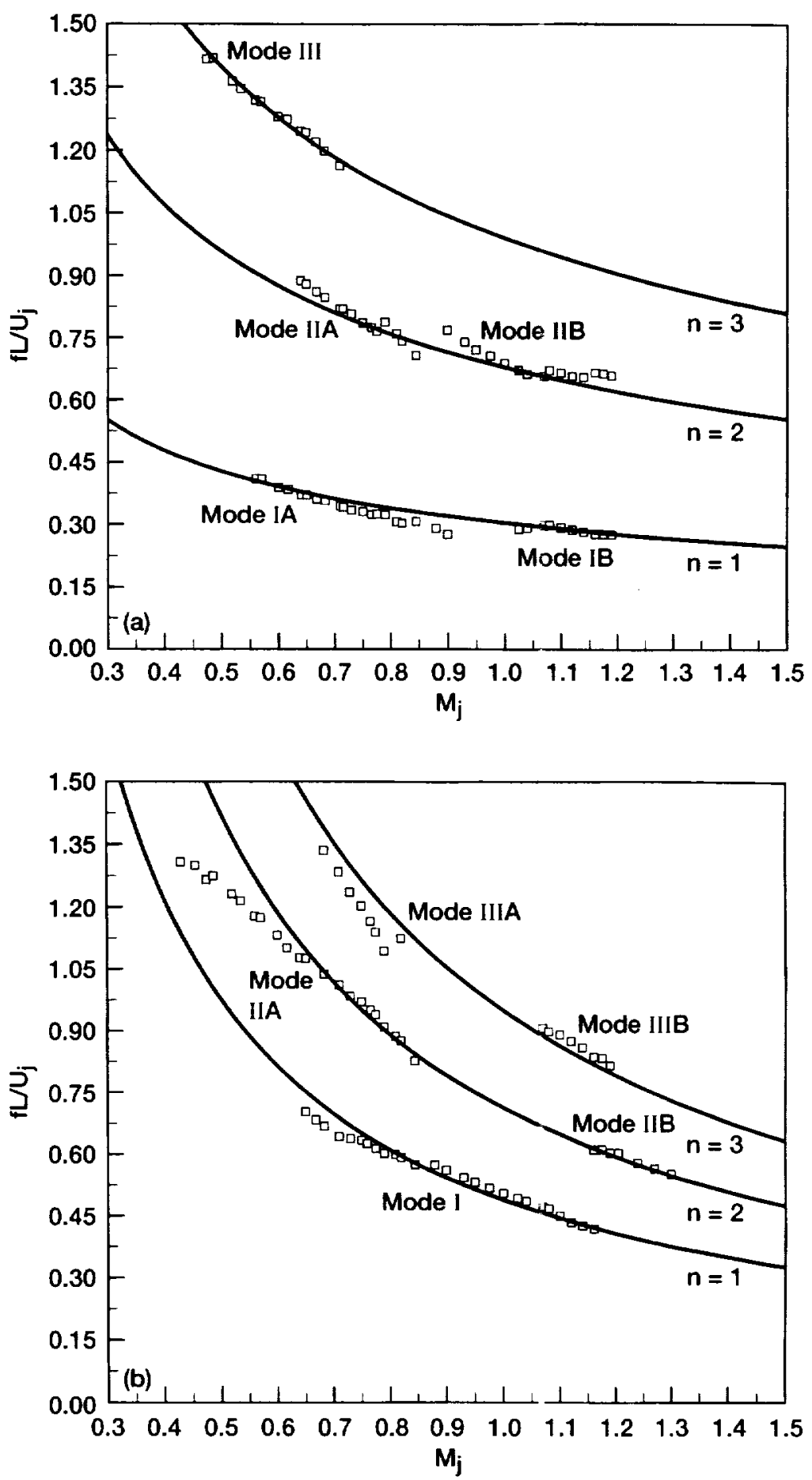

Figure 9.-Correlation for normalized frequency versus fully expanded jet Mach number (a) $L / D=3$ cavity. (b) $L / D=3$ cavity. 

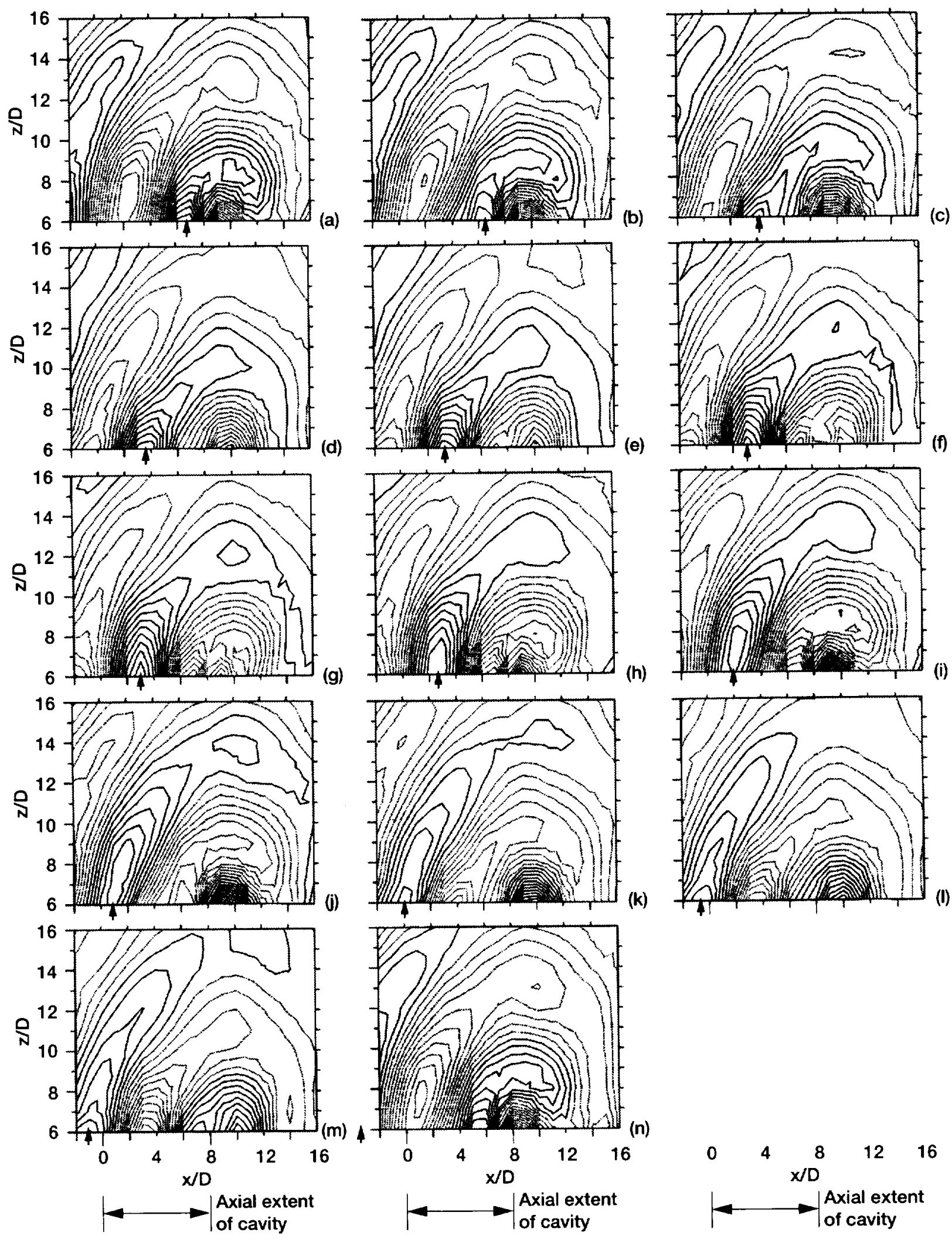

Figure 10.-Phase-averaged near acoustic field in the $x z$ plane for the $L D=8$ cavity. $M_{j}=1.1, y / D=0$. Parts (a)-(n) represent a full cycle. The phase difference from frame to frame is approximately $28^{\circ}$. Solid and dashed lines represent positive and negative phases of the feedback wave. 

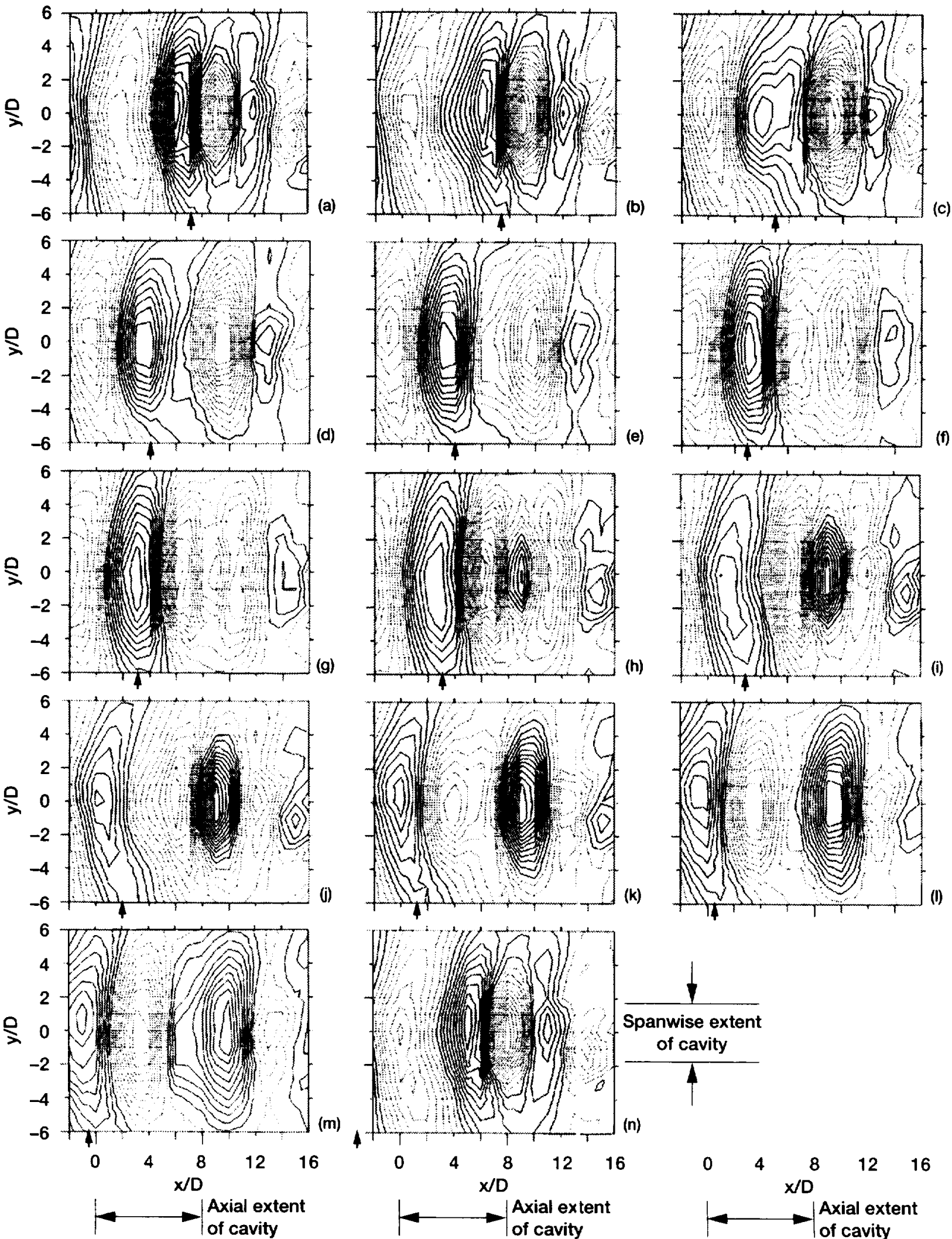

Figure 11. - Phase-averaged near acoustic field in the xy plane for the $L D=8$ cavity. $M_{j}=1.1, z / D=6$. Parts (a)-(n) represent a full cycle. The phase difference from frame to frame is approximately $28^{\circ}$. Solid and dashed lines represent positive and negative phases of the feedback wave. 

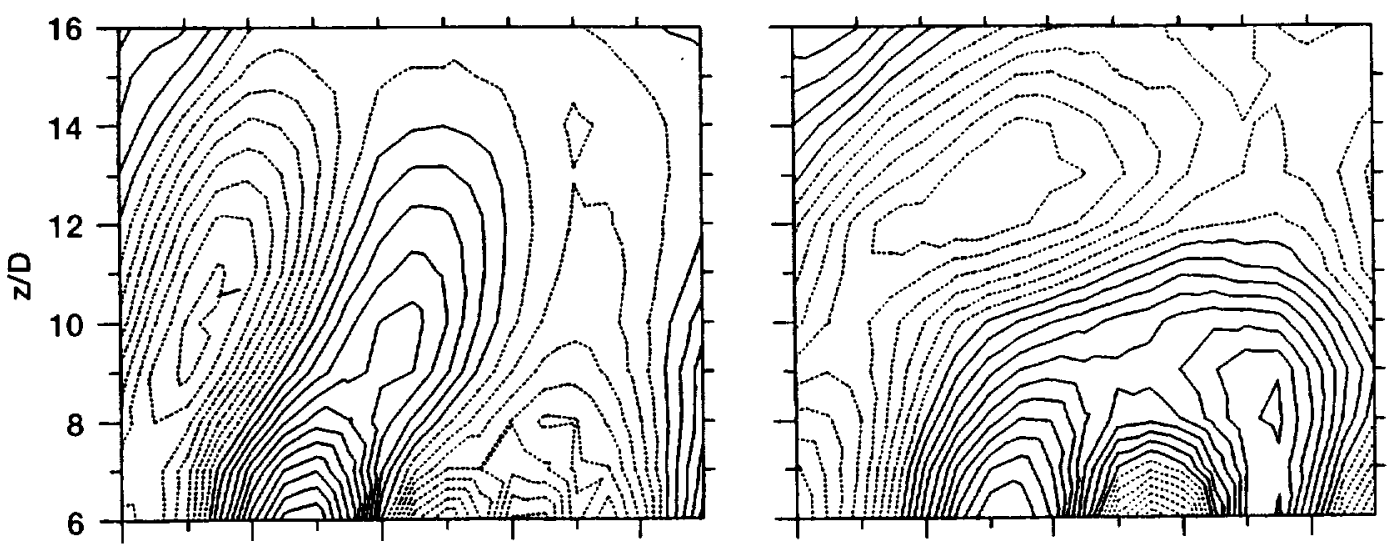

(a)

(c)
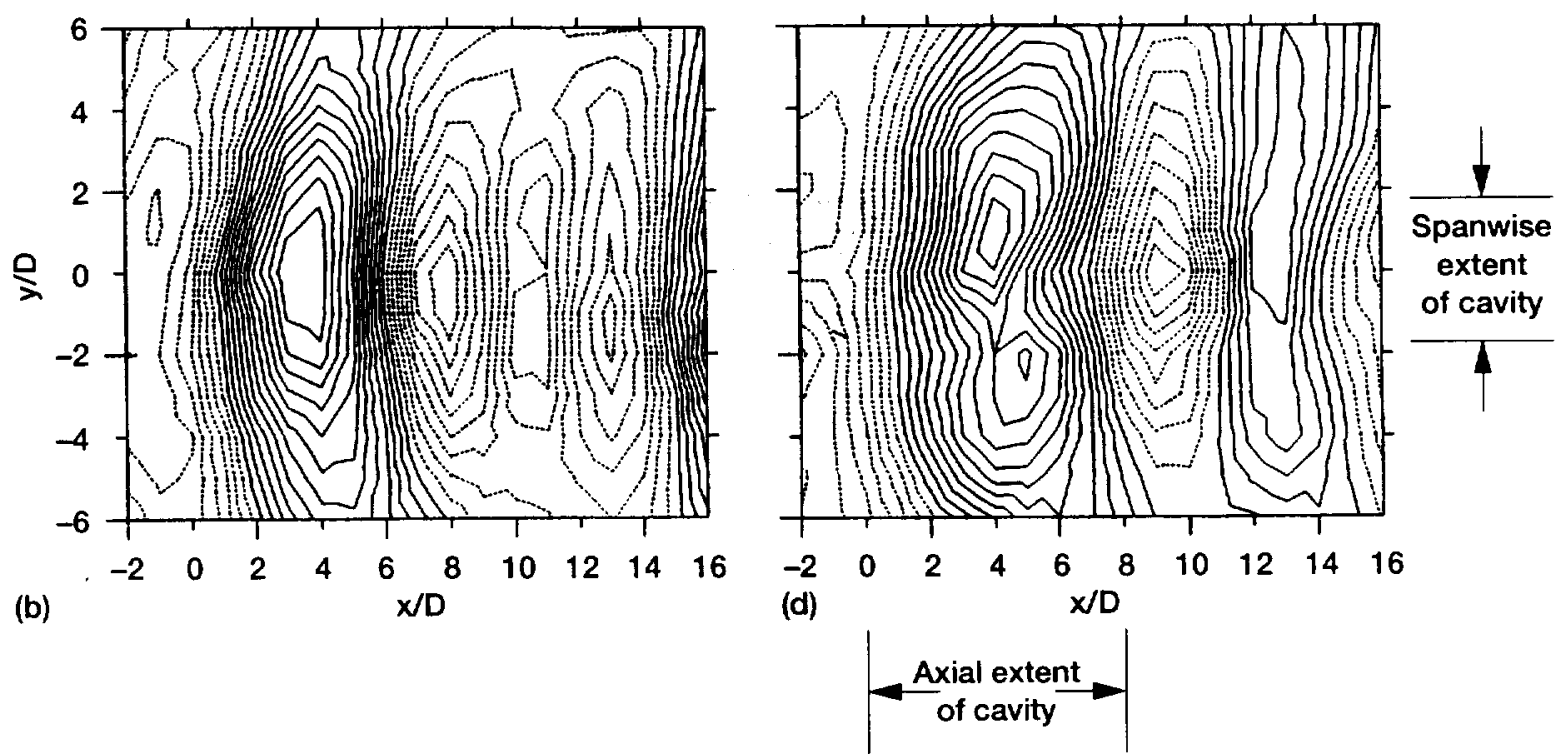

Figure 12.-Phase-locked acoustic near field of jet screech compared to that for jet-cavity interaction $(\mathrm{LD}=8)$, both at $M_{j}=1.23$. (a) Screech, $x z$ plane. (b) Screech, $x y$ plane. (c) Jet-cavity interaction, Xz plane. (d) Jet-cavity interaction, xy plane. 


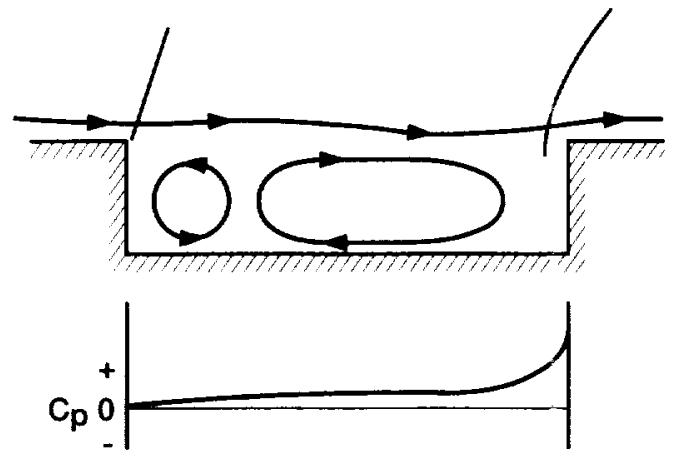

(a)

Open-cavity flow
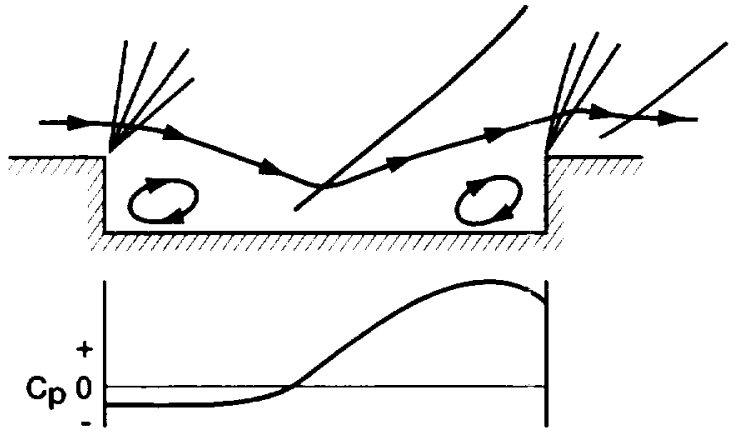

(b) Transitional-cavity flow

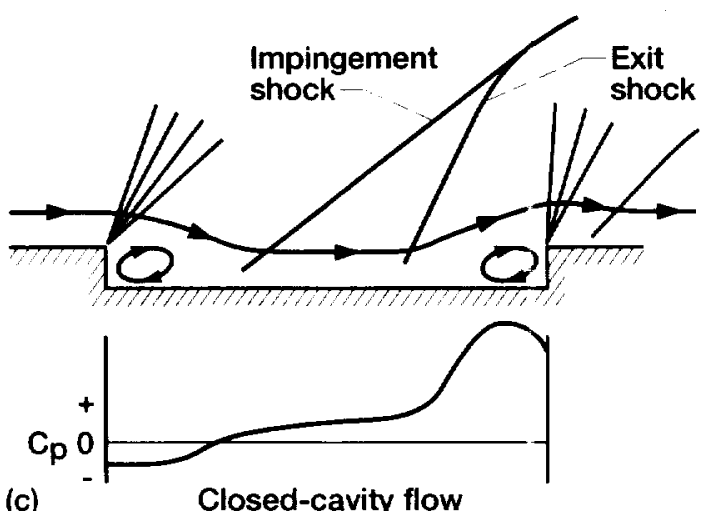

(c)

Closed-cavity flow

Figure 13. - Characterization of supe-sonic flow over cavities and associated f ressure distribution on the cavity floor (from Stallings \& Wilcox (1987)). (a) Open-cavity flow. (b) Transitional-cavity flow. (c) Closed-cavity flow. 


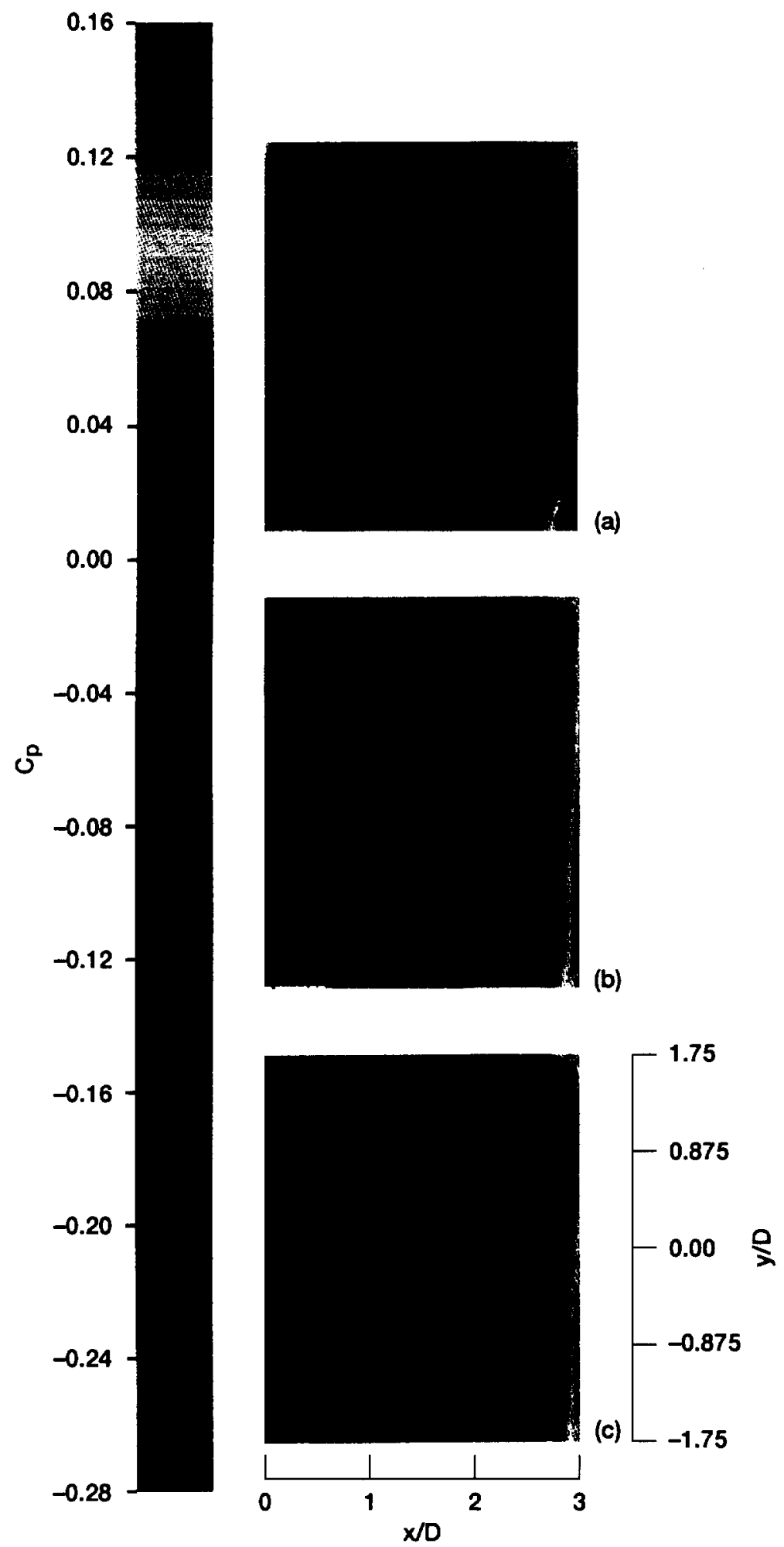

Figure 14. - Photoluminescent pressure sensitive paint results for the $L / D=3$ cavity at various jet Mach numbers. $M_{j}(a) 1.02$, (b) 1.1, (c) 1.17 . 


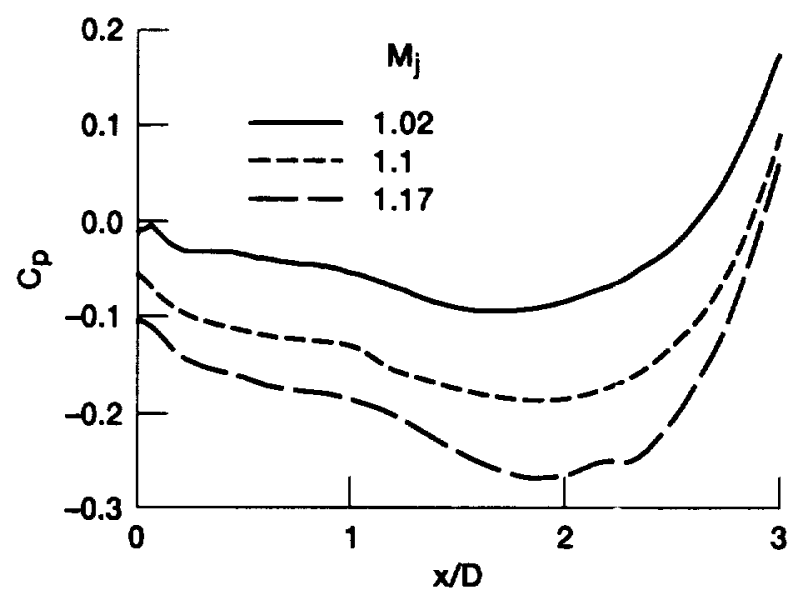

Figure 15. - Centerline pressure coefficierits derived from pressure sensitive paint for the $L D=3$ cavity.

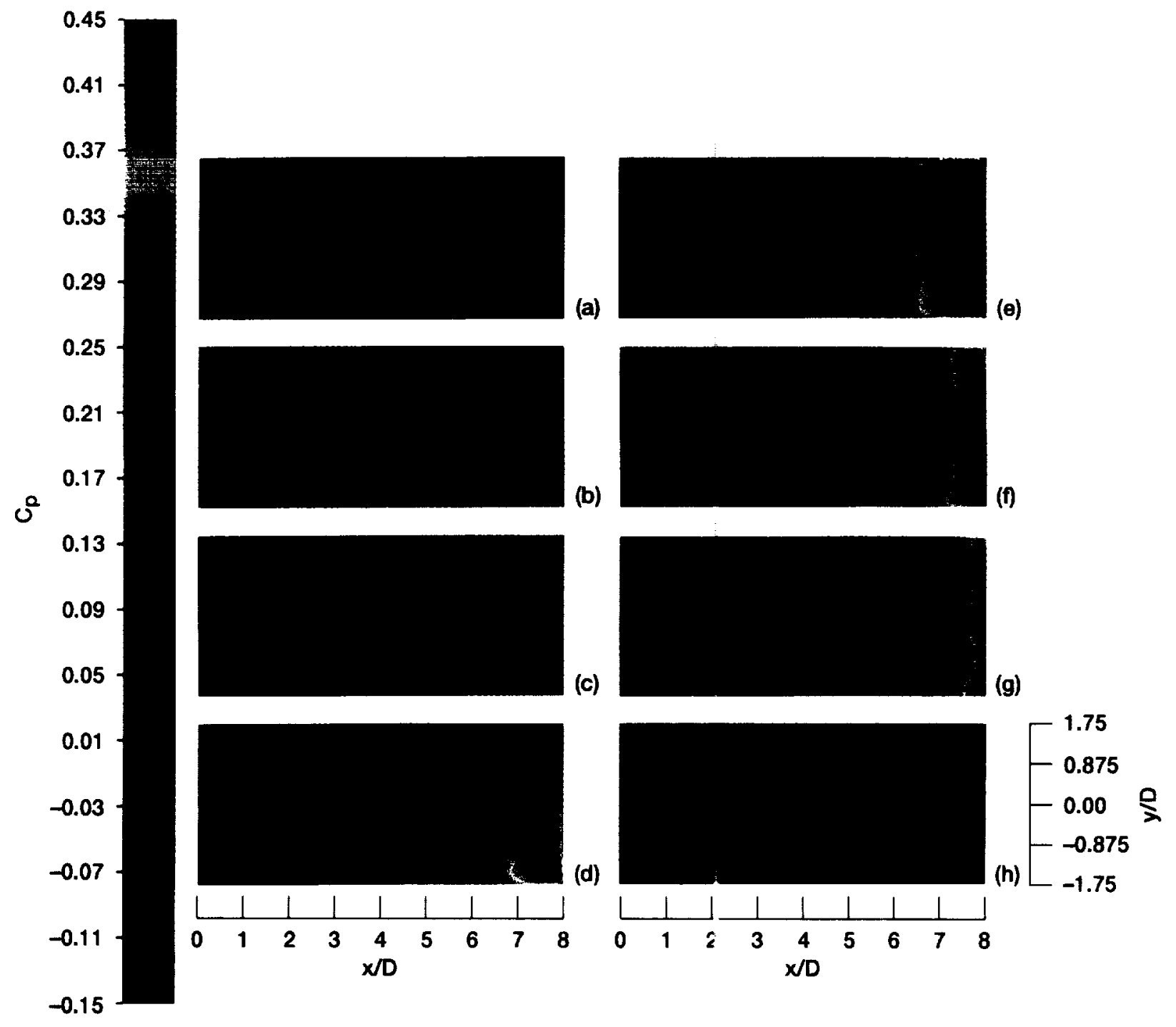

Figure 16. - Photoluminescent pressure sensitive paint results for the $L D=8$ cavity at various jet Mach numbers. $M_{\mathrm{j}}$ (a) 0.615, (b) 0.75, (c) 0.865, (d) 0.97, (e) 1.02, (f) 1.13, (g) 1.23, (h) 1.32 . 
Public reporting burden for this collection of information is estimated to average 1 hour per response, including the time lor reviewing instructions, searching existing data sources, gathering and maintaining the data needed, and completing and reviewing the collection of infomation. Send comments regarding this burden estimate or any other aspect of this collection of information, including suggestions for reducing this burden, 10 Washington Headquarters Services, Directarate for Intormation Operations and Reports, 1215 Jefferson Davis Highway. Suite 1204. Aftington, VA 22202-4302, and to the Otlice of Management and Budget, Papenwork Reduction Project (0704-0188), Washington, DC 20503.

\begin{tabular}{|l|l|l|}
\hline 1. AGENCY USE ONLY (Leave blank) & $\begin{array}{c}\text { 2. REPORT DATE } \\
\text { November } 1998\end{array}$ & $\begin{array}{r}\text { 3. REPOAT TYPE AND DATES COVERED } \\
\text { Technical Memorandum }\end{array}$ \\
\hline
\end{tabular}

\section{TITLE AND SUBTITLE}

Tone Noise and Nearfield Pressure Produced by Jet-Cavity Interaction

\section{AUTHOR(S)}

Ganesh Raman, Edmane Envia, and Timothy J. Bencic

7. PERFORMING ORGANIZATION NAME(S) AND ADDRESS(ES)

National Aeronautics and Space Administration

Lewis Research Center

Cleveland, Ohio 44135-3191

5. FUNDING NUMBERS

WU-522-31-23-00

9. SPONSORING/MONITORING AGENCY NAME(S) AND ADDRESS(ES)

National Aeronautics and Space Administration

Washington, DC 20546-0001
8. PERFORMING ORGANIZATION REPORT NUMBER

E-11381
10. SPONSORING/MONITORING AGENCY REPORT NUMBER

NASA TM-1998-208836

AIAA-99-0604

\section{SUPPLEMENTARY NOTES}

Prepared for the 37th Aerospace Sciences Meeting \& Exhibit sponsored by the American Institute of Aeronautics and Astronautics, Reno, Nevada, January 11-14, 1999. Ganesh Raman, Dynacs Engineering Co., Inc., 2001 Aerospace Parkway, Brook Park, Ohio 44142 (work funded by NASA Contract NAS3-27186); Edmane Envia and Timothy J. Bencic, NASA Lewis Research Center. Responsible person, Ganesh Raman, organization code 5860, (216) $977-1102$

12a. DISTRIBUTIONAAVAILABILITY STATEMENT 12b. DISTRIBUTION CODE

Unclassified - Unlimited

Subject Category: 02

Distribution: Nonstandard

This publication is available from the NASA Center for AeroSpace Information, (301) 621-0390.

13. ABSTRACT (Maximum 200 words)

Cavity flow resonance can cause numerous problems in aerospace applications. While our long-term goal is to understand cavity flows well enough to devise effective cavity resonance suppression techniques, this paper describes a fundamental study of resonant tones produced by jet-cavity interaction at subsonic and supersonic speeds. Our specific jet-cavity configuration can also be used as a test bed for evaluating active and passive flow resonance control concepts. Two significant findings emerge from this study. 1) Originally, we expected that tones produced by jet-cavity interaction would resemble cavity tones or jet tones or would involve some simple combinations of each. The experimental data do not support these expectations: instead, the jet cavity interaction produce a unique set of tones. We propose simple yet and physically insightful correlations for these tones. Although the pressure patterns on the cavity floor display very complex variations with the Mach number for a length/depth $=8$ cavity, the tones correspond to the acoustic modes of the cavity-independent of flow. For a length/ depth $=3$ cavity, however, a surprise emerges: the pressure patterns on the cavity floor are not so complex but the tones depend significantly on the flow. Additionally, we examine the role of external feedback unique to jet-cavity interaction. 2) Previous research led us to expect that traditional classifications (open, transitional, or closed) for cavities in an infinite flight stream would be insensitive to small changes in Mach number and would depend primarily on cavity length/depth ratios. Use of the novel high resolution photoluminescent pressure sensitive paint shows that the classifications are actually quite sensitive to jet Mach number for a length/depth $=8$ cavity. However, these classifications provide no guidance whatsoever for tone amplitude or frequency. Detailed experimental data and insights presented here will assist researchers who are performing numerical simulations of jet-cavity flows as a first step toward devising resonance suppression methods.

\begin{tabular}{|c|c|c|}
\hline $\begin{array}{l}\text { 14. SUBJECT TERMS } \\
\text { Jets; Cavities; Resonance }\end{array}$ & Screech & \\
\hline $\begin{array}{l}\text { 17. SECURITY CLASSIFICATION } \\
\text { OF REPORT } \\
\text { Unclassified }\end{array}$ & $\begin{array}{l}\text { 18. SECURITY CLASSIFICATION } \\
\text { OF THIS PAGE } \\
\text { Unclassified }\end{array}$ & $\begin{array}{l}\text { 19. SECURITY CLASSIFICATION } \\
\text { OF ABSTRACT } \\
\text { Unclassified }\end{array}$ \\
\hline
\end{tabular}

NSN 7540-01-280-5500

15. NUMBER OF PAGES 35 16. PRICE CODE $\mathrm{A} 03$

20. LIMITATION OF ABSTRACT Standard Form 298 (Rev. 2-89) Prescribed by ANSI Std. Z39-18 298-102 

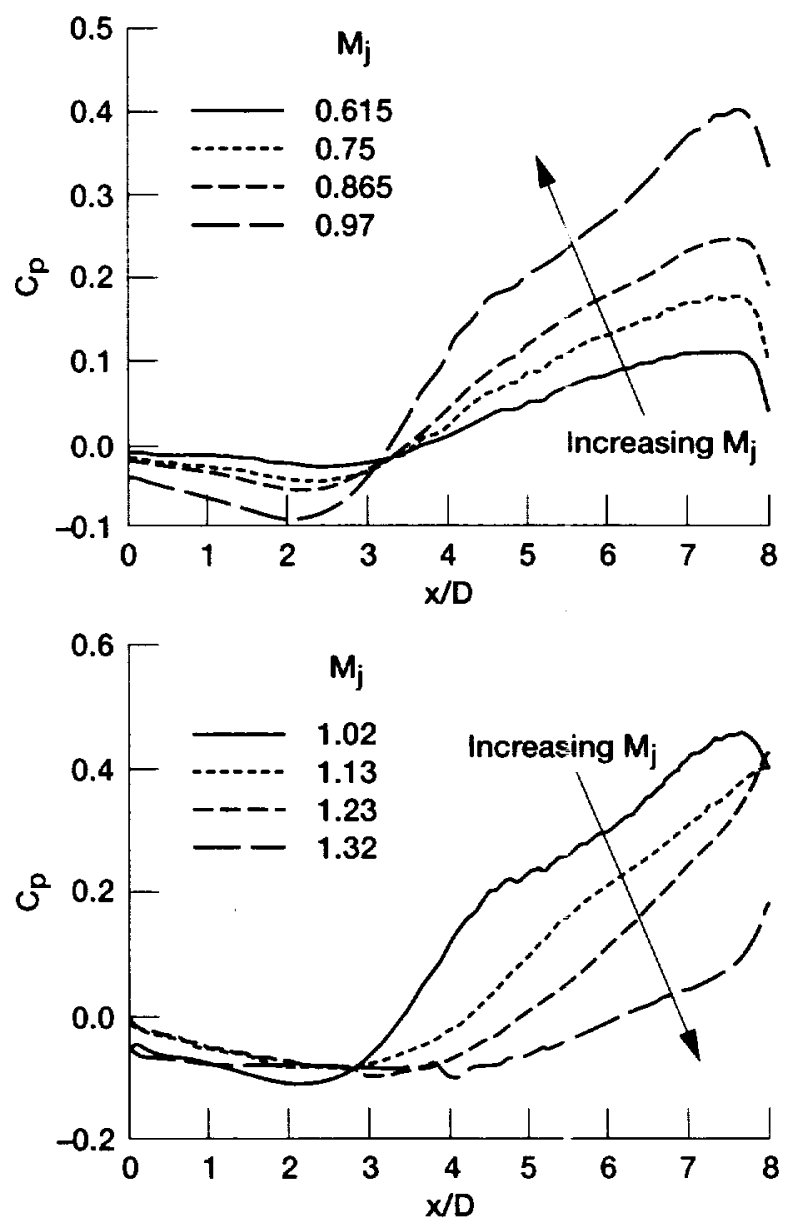

Figure 17.-Centerline pressure coefficients derived from pressure sensitive paint for the $L / D=8$ cavity. (a) $M_{j}=0.615-0.97$; (b) $M_{j}=1.02-132$. 